\title{
A Comparative Evaluation of a Mesoscale Model and Atmospheric Global Circulation Model for Air Quality Simulation: A Multiscale, Multisite Evaluation
}

\author{
P. Goswami and J. Baruah \\ CSIR Centre for Mathematical Modeling and Computer Simulation (CMMACS), NAL Belur Campus, Wind Tunnel Road, \\ Bangalore 560 037, India \\ Correspondence should be addressed to J. Baruah, juri.barua7@gmail.com
}

Received 30 March 2012; Accepted 13 May 2012

Academic Editors: D. Contini, J. A. Pudykiewicz, and A. Saha

Copyright ( $) 2012$ P. Goswami and J. Baruah. This is an open access article distributed under the Creative Commons Attribution License, which permits unrestricted use, distribution, and reproduction in any medium, provided the original work is properly cited.

Concentrations of atmospheric pollutants are strongly influenced by meteorological parameters like rainfall, relative humidity and wind advection. Thus accurate specifications of the meteorological fields, and their effects on pollutants, are critical requirements for successful modelling of air pollution. In terms of their applications, pollutant concentration models can be used in different ways; in one, short term high resolution forecasts are generated to predict and manage urban pollution. Another application of dynamical pollution models is to generate outlook for a given airbasin, such as over a large city. An important question is application-specific model configuration for the meteorological simulations. While a meso-scale model provides a high-resolution configuration, a global model allows better simulation of large-sale fields through its global environment. Our objective is to comparatively evaluate a meso-scale atmospheric model (MM5) and atmospheric global circulation model (AGCM) in simulating different species of pollutants over different airbasins. In this study we consider four locations: ITO (Central Delhi), Sirifort (South Delhi), Bandra (Mumbai) and Karve Road (Pune). The results show that both the model configurations provide comparable skills in simulation of monthly and annual loads, although the skill of the meso-scale model is somewhat higher, especially at shorter time scales.

\section{Introduction}

Atmospheric pollution models, either interfaced or coupled with dynamical models of atmosphere, can provide powerful tools for many applications. A number of models of varying complexity have been proposed in the recent past to estimate the concentration of pollutants in the atmosphere [1-3]. In addition to their sources, concentrations of pollutants are also strongly influenced by meteorological parameters like rainfall, relative humidity, and wind speed. Thus accurate specifications of the meteorological fields, and their effects on pollutants, are critical requirements for successful modelling of air pollution. In terms of their applications, pollutant concentration models can be used in different ways; in one, short-term high-resolution forecasts are generated to predict and manage urban pollution [4]; interfaced with geographical information system (GIS), such model can provide powerful tools for pollution management. Thus a GIS-based air pollution modeling in developed [5] to measure the concentration of carbon monoxide (CO) and nitrogen dioxide $\left(\mathrm{NO}_{2}\right)$ for six highways of Tehran for each vehicle. Another application of dynamical pollution model is to generate outlook for a given Air basin, such as over a large city. The focus of the present work is on the latter application; the objective is to comparatively evaluate two dynamical model configurations in simulating four species of pollutants over different locations.

A critical requirement for successful simulation of spatial and temporal variability of pollutants is prescription of the meteorological fields at high spatiotemporal resolution. Such high-resolution simulation of meteorological fields requires use of meso-scale atmospheric models. The mesoscale models today can support horizontal grid spacing down to a few hundreds of meters. For air quality applications 
TABLE 1: Data on total number of vehicles and parameters for vehicular source.

\begin{tabular}{|c|c|c|c|c|c|c|}
\hline \multirow{2}{*}{ Parameter } & \multirow{2}{*}{ Location } & \multicolumn{4}{|c|}{ Types of vehicles } & \multirow{2}{*}{ Total } \\
\hline & & Two wheeler & Diesel-driven car & Petrol-driven car & Heavy vehicles & \\
\hline \multirow{3}{*}{ Number of vehicle } & ITO (Delhi) & $3,797,943$ & 104,020 & $1,85,9370$ & 230,398 & $6,011,731$ \\
\hline & Bandra (Mumbai) & $19,00,042$ & $9,29,877$ & $3,45,024$ & $3,29,043$ & $35,42,824$ \\
\hline & Karve Road (Pune) & $11,23,898$ & 82,809 & $2,10,818$ & 27,839 & $14,45,364$ \\
\hline \multirow{3}{*}{ Average speed $(\mathrm{km} / \mathrm{hr})$} & ITO (Delhi) & 20.68 & 22.28 & 12.04 & 13.84 & - \\
\hline & Bandra (Mumbai) & 19.1 & 15.4 & 16.6 & 15.5 & - \\
\hline & Karve Road (Pune) & 26.4 & 19 & 22 & 16.5 & 一 \\
\hline \multicolumn{2}{|c|}{ Average distance traveled by types of vehicles $(\mathrm{km} / \mathrm{hr})$} & 21.37 & 19.37 & 22.71 & 11.84 & - \\
\hline
\end{tabular}

Source: Centre for Science and Environment, Transport Department, Government of National Capital Territory (NCT) of Delhi, Mumbai Environmental Social Network and Pune Municipal Corporation 2007, and Pune Vehicle Activity Study 2004 [18].

for urban mesoscale modeling, wind direction and wind speed are important factors for advection and diffusion of pollutants $[6,7]$. However, although air pollution modeling has seen significant improvements in recent years in general [8-10], the use of dynamical, in particular, meso-scale models for modeling pollution is relatively still limited in many aspects $[11,12]$.

In addition to simulation and forecasting of urban air pollution at short time scales, dynamical models can also help in generating seasonal outlook of pollution concentrations. However, such applications necessarily require a larger domain, not generally practical with meso-scale model with high resolution. At the same time, while the advantages of using meso-scale models to support high spatial resolution are obvious, there are dynamical and physical reasons to believe that a global atmospheric circulation model (AGCM) may be an equally good or even better alternative for certain applications. In particular, a meso-scale model may not be the best tool for seasonal outlook in view of its limited domain. An AGCM, on the other hand, has the ability, at least in principle, to support long lead due to its global setting. In the present work, we assess the skill of simulation of air pollution using a meso-scale atmospheric model (MM5) and an AGCM with equal lead (24 hours) over a number of urban sites.

It was shown that an air pollution model, driven by either NCEP reanalysis or by the AGCM-generated fields, can successfully reproduce the concentrations for the Delhi Air basin $[13,14]$. We adopt the same mathematical representation of dynamics of the species as in our earlier study, $[13,14]$. The pollution model is then driven by location-specific sources and sinks.

In Section 2 we briefly describe the Air basin and various pollution data used for the present study. The air pollution model, already described in $[13,14]$, is outlined in Section 3, while brief descriptions of the AGCM configuration and mesoscale models are given in Section 4. The analysis procedure is described in Section 5 and the results are presented in Section 6. Section 7 contains our conclusions and perspectives.

\section{The Air basin and Pollution Data}

We consider three pollutants for our present study: respirable suspended particulate matter (RSPM), sulphur dioxide
$\left(\mathrm{SO}_{2}\right)$, and nitrogen dioxide $\left(\mathrm{NO}_{2}\right)$. The major sources of these pollutants in urban area are emissions from vehicles, industries, and domestic appliances. However, relative contribution of these sources varies from one urban location to another. The air pollution model has been evaluated for Delhi as a whole in our earlier study $[13,14]$. In this study we extend the scope of the model to include different locations: ITO (Central Delhi), Sirifort (South Delhi), Bandra (Mumbai), and Karve Road (Pune).

Mumbai is India's largest city (by population) located on the west coast. Air Quality Monitoring Network of MPCB (Maharashtra Pollution Control Board) collects air quality data at three stations in Mumbai; Sion, Mulund, and Bandra. We have considered the simulations for the Bandra Station because of availability of daily data for all the 365 days for the year 2010.

Pune is a growing city situated at $18^{\circ}$ to $19.2^{\circ}$ latitudes and $73.2^{\circ}$ to $75.1^{\circ}$ longitudes. The main source of air pollution for Pune is vehicular emission; there is an increase by nearly 300 vehicles everyday in Pune district [15]. We have used the observed pollution data for Karve Road, compiled by MPCB, Mumbai.

The numbers of vehicles for Bandra and Karve Road (Table 1) were taken from data compiled by Mumbai Environmental Social Network and Pune Municipal Corporation 2007, respectively. We have used data on the number of vehicles of 2007 for Pune city for the simulation of the concentration of the year 2010 due to the unavailability of data for that year. Average distances traveled by different vehicles for the two cities (Table 1) were taken from data compiled by the Centre for Science and Environment (http:// old.gobartimes.org/july1999/gtimes_cov3.htm). The data for emission rates of different pollutants for different vehicular type (Table 2 ) were adopted from $[16,17]$.

\subsection{Collection Method of Observed Air Pollutants' Concen-} tration. Sampling and measurement of air pollutants is generally known as air quality monitoring. Air quality monitoring is an integral component of any pollution control programme. Air quality measurement is generally carried out in two different situations. One is ambient air quality measurement, where the pollutant levels in the ambient atmosphere are measured. The second type of measurement generally deals with the pollutants emitted from a source. 
TABLE 2: Data on vehicular sources [9].

\begin{tabular}{|c|c|c|c|c|}
\hline \multirow[t]{2}{*}{ Vehicle type } & \multicolumn{4}{|c|}{$\begin{array}{c}\text { Emission rate }\left(E_{R}\right) \text { of pollutants in } \mathrm{gm} / \mathrm{km} \text { by } \\
\text { different vehicles }\end{array}$} \\
\hline & Two wheeler & Diesel car & Petrol car & Heavy vehicles \\
\hline SPM & 0.2 & 2.0 & 0.33 & 3.0 \\
\hline RSPM & 0.2 & 2.0 & 0.33 & 3.0 \\
\hline $\mathrm{SO}_{x}$ & 0.02 & 0.39 & 0.08 & 1.5 \\
\hline $\mathrm{NO}_{x}$ & 0.07 & 0.99 & 3.2 & 2.1 \\
\hline
\end{tabular}

In our study, the validation is carried out against the ambient air quality data generated by the Central Pollution Control Board, India (CPCB), for the period 2000-2005. Some details of the measurements are given in Table 3.4 [19, 20]. The sample for RSPM is collected for every 8 hours throughout the day while the sampling period of $\mathrm{SO} x$ and $\mathrm{NO} x$ is 4 hourly. CPCB compiles the data from its network and provides daily values of pollutants over Delhi.

High-volume sampler (HVS) is used for sampling large volumes of an atmosphere for collection of samples of respirable dust particulate matter $\left(\mathrm{PM}_{10}\right)$ by respirable dust sampler (RDS) [21, 22]. HVSs, having impingers (bubbler trains) in series with sodium tetrachloromercurate as absorbing solution, were operated at an average flow rate of 0.5 $\mathrm{L} / \mathrm{min}$. for collection of $\mathrm{SO}_{2}$ [23] for $24 \mathrm{~h}$. In the case of collection of NOx, sodium hydroxide was used as absorbing solution and collected at an average flow rate of $0.5 \mathrm{~L} / \mathrm{min}$ for $24 \mathrm{~h} \mathrm{[24].} \mathrm{The} \mathrm{impinger} \mathrm{samples} \mathrm{were} \mathrm{put} \mathrm{in} \mathrm{ice} \mathrm{boxes} \mathrm{imme-}$ diately after sampling and transferred to a refrigerator prior to analysis [25]. The samples were analysed spectrophotometrically, using West and Gake methods and Jackob and Hocheiser's modified methods for analysis of SOx and $\mathrm{NO} x$, respectively [26]. RSPM is computed after weighing the filter paper before and after sampling. The filter paper was conditioned in a dry atmosphere before weighing [27].

\section{The Air Pollution Model}

The mathematical representation of dynamics of a species as well as the sources and sinks is as described in [13, 14]. However, we outline them here for completeness. The basic dynamics of a species is governed by the continuity equation for a scalar variable $[8,28]$; to apply our model to the Delhi Air basin, we consider area-averaged concentration (s) of species in an atmospheric area $\left(\mu \mathrm{g} \mathrm{m}^{-3}\right)$. As in [13], we neglect the transport of pollutants in the vertical due to advection [29] at daily and longer time scale, although it may have important contribution at short time scales.

We consider the same formulations for the sources and the sinks as in $[13,14]$. The sources of species concentrations are vehicular exhaust $\left(S_{V}\right)$ wind-blown dust $\left(S_{W}\right)$ and domestic appliances $\left(S_{D}\right)$; the primary sinks of species are precipitation $\left(S_{P}\right)$ and removal due to advection $\left(S_{A}\right)$. As the downward settling time due to gravity is generally longer than a day, we do not include this term explicitly in the present formalism; however, effect of gravity is considered implicitly in prescribing the initial conditions, as described in the next section. The continuity equation is then integrated with observed concentration on day 1 as the initial condition for the second day forced by daily values of meteorological variables; the initial values of concentration for subsequent days are obtained from model simulations for the previous day [14].

While the basic equation is same for all the species, the forms of source and sink functions are chosen for each species [14]. It was shown that [14] both vehicular and domestic sources make significant contributions to daily values of concentrations, although the contribution from the vehicular sources was found to be by far the larger. Further, the contribution also varied with the season; the improvement due to inclusion of nonvehicular sources was found to be more significant for the winter months in Delhi [14], perhaps due to practices like more fossil fuel burning in these months. In the present work we shall therefore only discuss results with all sources. In the present work we have not considered active chemistry for the species; thus the work should be considered a minimal forecast model, especially for $\mathrm{SO}_{2}$ and $\mathrm{NO}_{2}$.

\section{Meteorological Forecast Models}

4.1. The AGCM Configuration, Model Domain, and Initial Conditions. We adopt an AGCM with variable resolution (stretched coordinate with a zoom), which allows relatively higher resolution (zoom) over a chosen domain in a continuous and dynamically consistent manner. The principle and the formulation as well as validation of the model adopted here (LMDZ.3 from LMD, France), including formulation of variable resolution, have been described in detail in earlier works $[30,31]$. The variable resolution is prescribed as a continuous variation (stretching) in the resolution with respect to a point using a function like a sine or tanh (used here). The vertical coordinate is hybrid sigma system with 19 levels in the present version. The model physics in the present study uses a diurnal cycle, a land surface module, and convective parameterization scheme of Tiedtke [32]. The model has been tested and validated for the Indian region at different scales [33-35]. We use a configuration similar (except in resolution) to the one used in $[34,35]$ for possible future coupling of the pollution model to an AGCM configuration validated for monsoon forecasting.

4.2. Mesoscale Model (MM5). The present study uses the non-hydrostatic version of meso-scale model MM5, version 3 developed originally by Anthes and Warner [36]. This fifthgeneration Pennsylvania State University/National Center for Atmospheric Research (PSU/NCAR) is a non-hydrostatic, terrain-following sigma-coordinate model, with extensive documentation and validation [37], designed to simulate or predict mesoscale and regional-scale atmospheric circulation. Detailed description of it is available at http://www .mmm.ucar.edu/mm5/. The most useful feature of the MM5 model is its flexibility in terms of many options that are user specified. The combination of multiple-nest capability, four-dimensional data assimilation technique, and a variety of physics options makes the model capable of simulation on smaller spatial scales, limited mainly by data resolution, 
quality, and computer resources [38]. The model allows options for parameterization of various processes like cumulus convection, planetary boundary layer (PBL), and radiative forcing. All simulations in this study were carried out with a single domain; the integration time step in seconds was chosen on the basis of $3 * d x$ criteria, where $\mathrm{dx}$ is grid size.

The relaxation boundary conditions [38] were used in all the simulations wherein outer row and column were specified by time-dependent values, whereas next four points are relaxed towards the boundary values with a linearly decreasing (away from boundary) relaxation constant. Global tropospheric analysis $1^{\circ} \times 1^{\circ}$ degree data (http://dss .ucar.edu/datasets/ds083.2/) from the National Center for Atmospheric Research (NCAR) was used to initialize the model. Terrestrial data includes terrain elevation (30minute), land-use (USGS-24 Category 30 minute), and vegetation fraction (10 minute). Terrain and vegetation fraction data sets are available from the University Corporation for Atmospheric Research (UCAR) ftp site (2009) ftp://ftp.ucar .edu/mesouser/MM5V3/TERRAIN_DATA/.

We have carried out simulation with AGCM fields with $192 \times 144$ grid points with a zoom factor of 2 over the zoom centre. This provides a resolution of about $50 \mathrm{~km}$ around the selected locations. The time step of integration was adopted as that for the high-resolution simulation [34] to avoid any numerical bias. The simulations with MM5 meteorological field are also carried out with about $30 \mathrm{~km}$ resolution for a comparison with simulations using AGCM fields. Table 3 summarizes the model configuration and various options used by MM5 in the present study (http:// www.mmm.ucar.edu/mm5/).

Initial and boundary conditions every 6 hours are obtained from the National Centers for Environmental Prediction Global Forecast System (NCEP GFS) (final) global-gridded analysis (FNL). For each forecast the model was integrated for 24 hours with the initial field at 0000 UTC of the previous day. The initial conditions were adopted from the daily fields of NCEP Reanalysis [39] for the respective years. The SST field was prescribed as the climatological monthly mean fields from the AMIP (http://www-pcmdi .llnl.gov/projects/amip/AMIP2EXPDSN/BCS_OBS/amip2 bcs.htm) dataset. Forcing methodology and physical parameterizations applied in MM5 and AGCM models in the present study are shown in Table 3.

\section{Multiscale Analysis and Validation}

In the present case, the skill in simulating the pollutants depends both on the quality of simulation of the meteorological fields by the AGCM and MM5 and the process model for pollution. We first consider an optimum AGCM configuration. It is well known that AGCM simulations are sensitive to choice of resolution $[40,41]$, parameterization scheme [34], and other parameters. However, optimization of the model configuration can significantly improve skill [35]. It should be noted, however, that systematic bias in the AGCM simulations can be removed through calibration and optimization of processes in the pollution model that involve
TABLE 3: Model parameters used in MM5 and AGCM in the present study.

\begin{tabular}{lll}
\hline Parameter & MM5 & AGCM \\
\hline $\begin{array}{l}\text { Model version } \\
\text { Horizontal resolution } \\
(\mathrm{km})\end{array}$ & NCAR MM5V3 & LMDZ.3 \\
$\begin{array}{l}\text { Vertical levels } \\
\text { Convective }\end{array}$ & 23 & 50 \\
parameterization & Anthes-Kuo & 19 \\
$\begin{array}{l}\text { Microphysical scheme } \\
\text { PBL }\end{array}$ & Simple ice & Tidtke \\
$\begin{array}{l}\text { Radiation scheme } \\
\text { Land surface process }\end{array}$ & $\begin{array}{l}\text { Dudhia } \\
\text { NOAH LSM }\end{array}$ & LMD \\
$\begin{array}{l}\text { Lateral boundary } \\
\text { condition }\end{array}$ & Relaxation & LMD \\
Initial condition & $\begin{array}{l}\text { Global tropospheric } \\
\text { analysis } 1^{\circ} \times 1^{\circ}\end{array}$ & $\begin{array}{l}\text { NCEP reanalysis } \\
\text { data, 2.5 } \times 2.5^{\circ}\end{array}$ \\
Forecast lead & degree data $($ NCAR) & resolution \\
Nonhydrostatic & Yes & 5 days \\
\hline
\end{tabular}

these processes. The optimization of the AGCM configuration is carried out by comparing simulations for a given year (2000) with observations over Delhi for rainfall, wind, and temperature. It may be noted, however, that the effects of the simulated meteorological fields on the simulation of the pollutants depend on the strengths of the parameters in the pollution model; these semiempirical parameters are used to optimize the skill.

To optimize the pollution model, we consider the error

$$
e(\alpha)=\frac{1}{365} \sum_{i=1}^{365}\left|S_{s}(i, \alpha)-S_{o}(i, \alpha)\right|
$$

where $S_{s}(i, \alpha)$ and $S_{o}(i, \alpha)$ are, respectively, the simulated and observed values of daily concentrations for the day $i$, for a given value of the parameter $\alpha$. We then carry out a search procedure to arrive at the combination that provides minimum error given by (1). The search procedure is carried out by searching for a value of the parameter, through simultaneous variations in all the parameters in prescribed ranges varied within its range of uncertainty, to produce optimum performance (minimum error) on a few (15-20) days spread across a year (2000), and then the set of the parameters were then kept constant for the other days and the other years.

The values of the coefficients for static and dynamic sources used in earlier studies with dynamical fields from NCEP reanalysis ([13] and [14]) were recalibrated for AGCM-generated fields as well as for the MM5 model. These values for static and dynamic sources for ITO (Delhi) and Sirifort (Delhi) are described in Tables 4(a) and 4(b), while for Bandra (Mumbai) and Karve Road (Pune), these coefficients were recalibrated (Tables 4(a) and 4(b)). However, the differences between the two sets of parameters either for static or dynamic sources and sinks (Tables 4(a) and 4(b), resp.) are marginal. Thus a transition from NCEP reanalysis to AGCM for the meteorological fields involves no structural 
TABle 4: (a) Coefficients for different sources and sinks (static) for ITO (Delhi), Sirifort (Delhi), Bandra (Mumbai), and Karve Road (Pune). (b) Coefficients for different sources and sinks (dynamic) for ITO (Delhi), Sirifort (Delhi), Bandra (Mumbai) and Karve Road (Pune).

(a)

\begin{tabular}{|c|c|c|c|c|c|c|c|}
\hline \multirow[t]{2}{*}{ locations } & \multirow[t]{2}{*}{ Cases } & \multicolumn{6}{|c|}{$\begin{array}{l}\text { Coefficient of } \\
\text { fossil fuel }\end{array}$} \\
\hline & & NCEP & AGCM and MM5 & NCEP & AGCM and MM5 & NCEP & AGCM and MM5 \\
\hline \multirow{3}{*}{ ITO and Sirifort (Delhi) } & RSPM & 0.14 & 0.11 & 22 & 22 & 0.12 & 0.10 \\
\hline & $\mathrm{SO}_{2}$ & 0.03 & 0.03 & 30 & 34 & 2 & 1.6 \\
\hline & $\mathrm{NO}_{2}$ & 0.08 & 0.09 & 25 & 25 & 1.8 & 1.5 \\
\hline \multirow{3}{*}{ Bandra (Mumbai) } & RSPM & 0.12 & 0.09 & 12 & 10 & 5 & 4 \\
\hline & $\mathrm{SO}_{2}$ & 0.01 & 0.02 & 10 & 7 & 5 & 3 \\
\hline & $\mathrm{NO}_{2}$ & 0.03 & 0.05 & 8 & 8 & 4 & 3 \\
\hline \multirow{3}{*}{ Karve Road (Pune) } & RSPM & 0.09 & 0.09 & 10 & 10 & 2 & 2 \\
\hline & $\mathrm{SO}_{2}$ & 0.01 & 0.03 & 7 & 5 & 3 & 2 \\
\hline & $\mathrm{NO}_{2}$ & 0.07 & 0.07 & 7 & 7 & 3 & 2 \\
\hline
\end{tabular}

(b)

\begin{tabular}{|c|c|c|c|c|c|c|c|c|c|c|c|}
\hline \multirow{3}{*}{ locations } & \multirow{3}{*}{ Cases } & \multicolumn{10}{|c|}{ Coefficients for different sources and sinks } \\
\hline & & \multicolumn{2}{|c|}{ Wind dust } & \multicolumn{2}{|r|}{ Rain } & \multicolumn{2}{|c|}{ Dew } & \multicolumn{2}{|c|}{ u-wind } & \multicolumn{2}{|c|}{ v-wind } \\
\hline & & NCEP & $\begin{array}{c}\text { AGCM } \\
\text { and MM5 }\end{array}$ & NCEP & $\begin{array}{c}\text { AGCM } \\
\text { and MM5 }\end{array}$ & NCEP & $\begin{array}{c}\text { AGCM } \\
\text { and MM5 }\end{array}$ & NCEP & $\begin{array}{l}\text { AGCM } \\
\text { and MM5 }\end{array}$ & NCEP & $\begin{array}{c}\text { AGCM } \\
\text { and MM5 }\end{array}$ \\
\hline \multirow{3}{*}{ ITO and Sirifort (Delhi) } & RSPM & 0.12 & 0.10 & 0.6 & 0.5 & - & - & 1.5 & 1.2 & 2.0 & 1.5 \\
\hline & $\mathrm{SO}_{2}$ & - & - & 1.4 & 1.6 & 15 & 18 & 0.04 & 0.03 & 0.05 & 0.06 \\
\hline & $\mathrm{NO}_{2}$ & - & - & 0.6 & 0.8 & 18 & 18 & 0.009 & 0.01 & 0.008 & 0.008 \\
\hline \multirow{3}{*}{ Bandra (Mumbai) } & RSPM & 0.15 & 0.14 & 0.9 & 0.8 & - & - & 1.8 & 1.6 & 2.2 & 1.9 \\
\hline & $\mathrm{SO}_{2}$ & - & - & 0.9 & 0.7 & 8 & 9 & 0.01 & 0.03 & 0.03 & 0.04 \\
\hline & $\mathrm{NO}_{2}$ & 一 & - & 0.9 & 0.8 & 12 & 13 & 0.005 & 0.003 & 0.004 & 0.006 \\
\hline \multirow{3}{*}{ Karve Road (Pune) } & RSPM & 0.12 & 0.14 & 0.8 & 0.9 & - & - & 2.0 & 2.2 & 1.8 & 2.2 \\
\hline & $\mathrm{SO}_{2}$ & - & - & 0.9 & 0.9 & 9 & 11 & 0.02 & 0.02 & 0.03 & 0.02 \\
\hline & $\mathrm{NO}_{2}$ & - & - & 0.9 & 0.8 & 10 & 11 & 0.004 & 0.003 & 0.002 & 0.002 \\
\hline
\end{tabular}

change in the model. It is recognized that the meteorological variables and the processes do not affect the various pollutants in identical ways; while wind-blown dust is a major source for SPM (suspended particulate matter), it has little effect on $\mathrm{SO}_{2}$. Similarly, rain is likely to have stronger scavenges effect on $\mathrm{SO}_{2}$ and $\mathrm{NO}_{2}$ due to implied chemistry. We have thus carried out optimization of these processes for each species independently.

5.1. Error Measures. Although our focus is on daily and monthly loads of pollutants, we have carried out our analysis at different scales of the three species. The absolute error in forecast for day $i$ and year $n$ is given by

$$
E(i, n)=\left|X_{F}(i, n)-X_{O}(i, n)\right| .
$$

We examine the average absolute error, defined as

$$
E(n)=\frac{1}{365} \sum_{i=1}^{365}\left|X_{F}(i, n)-X_{O}(i, n)\right|,
$$

where $N$ is the number of years and $X_{F}(i, n)$ and $X_{O}(i, n)$ are forecast and observe values of daily concentration for year $n$ and day $i$, respectively.
The monthly load, $S_{M}(m)$ for a year $n$, is defined as

$$
S_{M}(m)=\sum_{i=1}^{30} S(i, m),
$$

where $S(i, m)$ is the concentration for $i$ th day and $m$ th month of $n$th year.

The error between monthly observation and simulations is defined as

$$
E_{M}(m)=\sum_{i=1}^{30}\left(S_{F}(i, m)-S_{o}(i, m)\right),
$$

where $S_{F}(i, m)$ and $S_{o}(i, m)$ are the forecast and observe concentration for $i$ th day and $m$ th month.

The average error between monthly observation and simulations is defined as

$$
E_{A}=\frac{1}{12} \sum E_{M}(m)
$$

\section{Results}

6.1. Meteorological Simulations. As an indication of quality of the meteorological simulations from AGCM and MM5, 


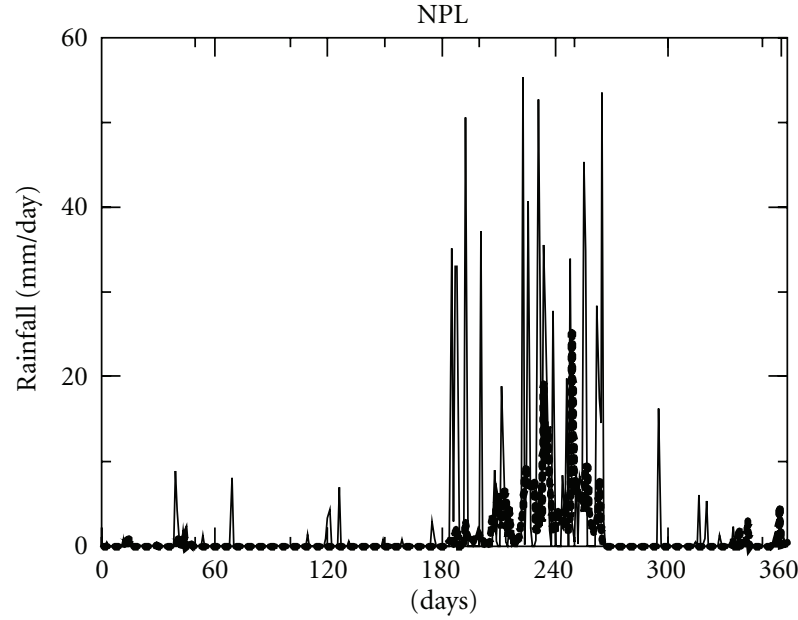

- Station

$\bullet$ MM5 (0.37)

(a)

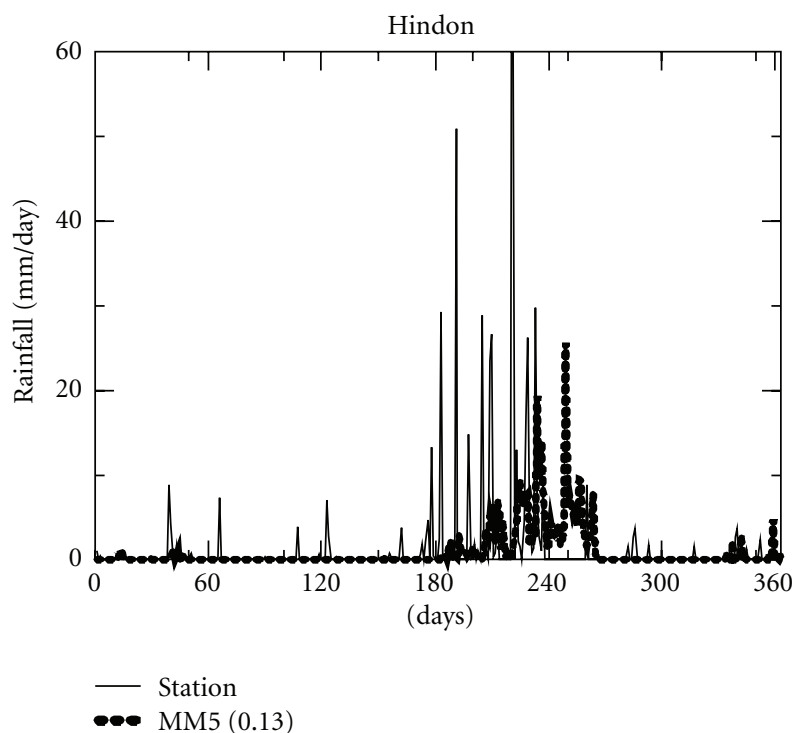

(c)

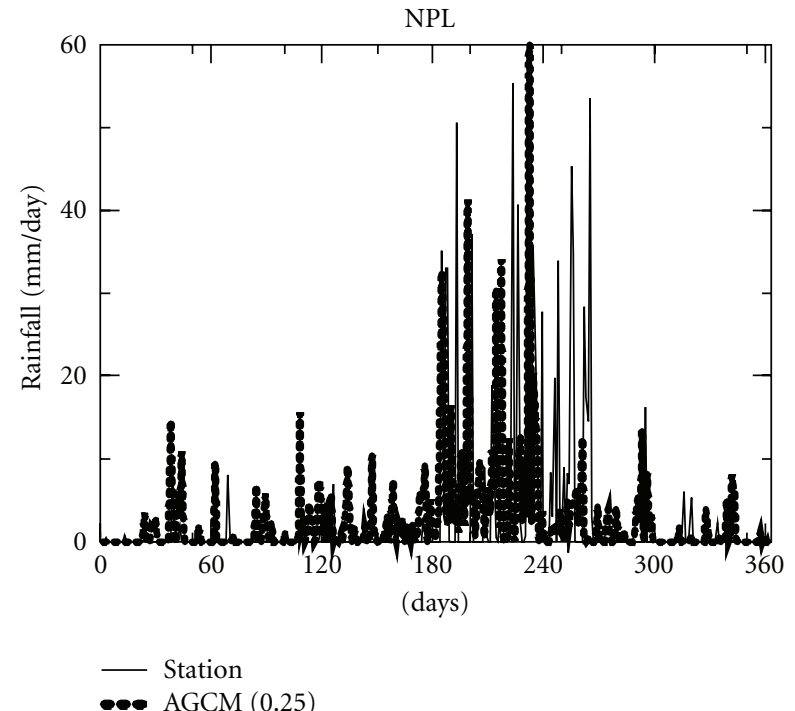

(b)

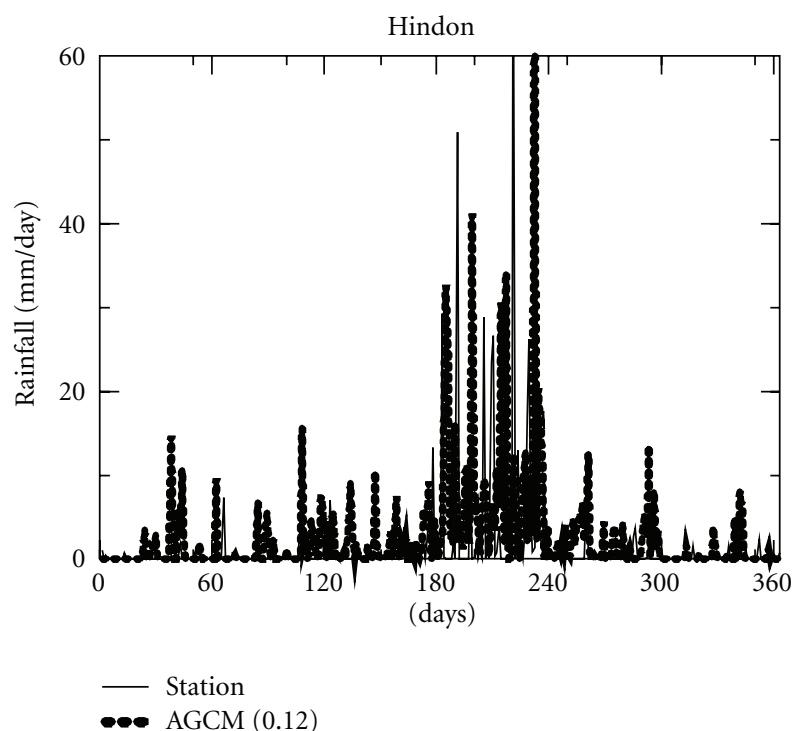

(d)

FIGURE 1: Comparison of observed and simulated values of daily rainfall over Delhi. The observations are from the CSIR Climate Observation and Modelling Network (COMoN) data at two stations: NPL and Hindon for the year 2010. The simulations are for the corresponding period from MM5 (left panels) and AGCM (right panels). The numbers in the brackets represent the correlation between observed and modeled data.

we have considered the annual cycles in daily rainfall from the two model configurations (Figure 1). In each case, the simulation is compared with observations averaged from four meteorological profilers over the Delhi region installed under the CSIR Climate Observation and Modelling Network $(\mathrm{COMoN})$. Under $\mathrm{COMoN}$, there are four 32-meter meteorological profilers at four locations over Delhi: NPL, Hindon, Narela, and Rajokri. It may be seen that both models generate simulations comparable to observations, although the correlation coefficients between daily rainfall from observation and simulation are significant: above 99\% (95\%) confidence level for the degrees of freedom involved. It is also clear that the simulations capture the differences among the rainfall at different locations, primarily due to different grid points involved in creating station averages.

6.2. Comparison of Simulation of Concentrations with MM5 and AGCM. Seasonal variations in RSPM, $\mathrm{SO}_{2}$, and $\mathrm{NO}_{2}$ levels over ITO (Delhi) year 2010 are depicted in Figure 2. The concentrations are high in winter months and premonsoon months and are low during monsoon months in both observed and simulated cycle. A plausible explanation for these results may be found by examining meteorological conditions. The monsoon results in large amount of precipitation and high wind speeds. Frequent rains wash down RSPM (Figure 2, top panels) and other pollutants $\mathrm{SO}_{2}$ and 


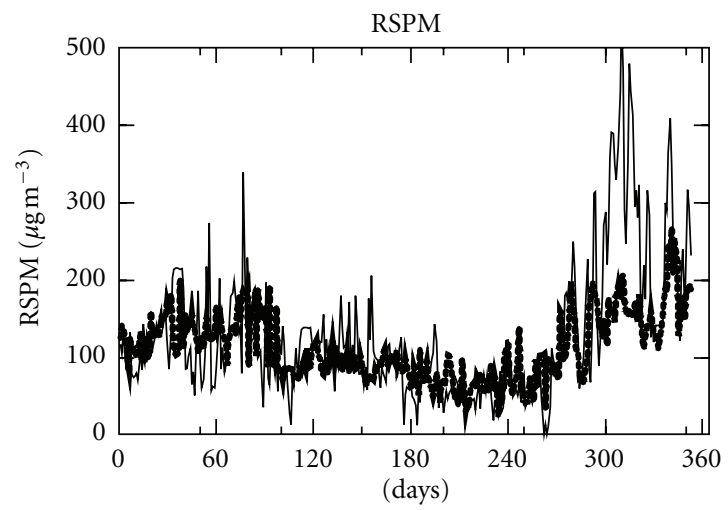

- Observed

œ• Prediction with MM5 (0.62)

(a)

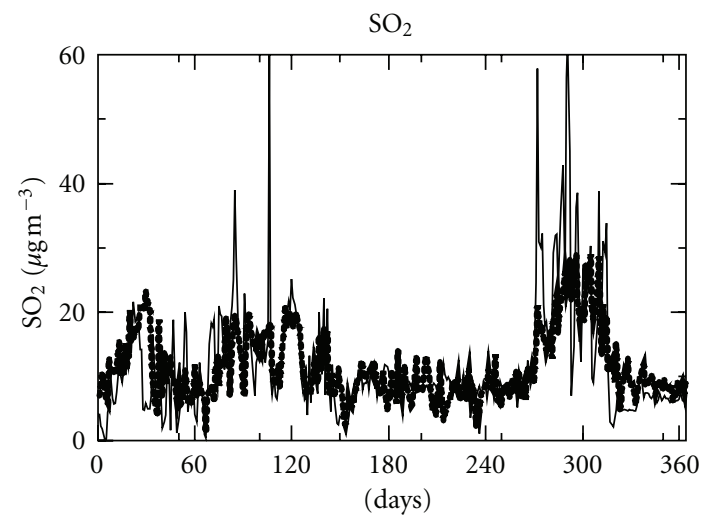

- Observed

••• Prediction with MM5 (0.62)

(c)

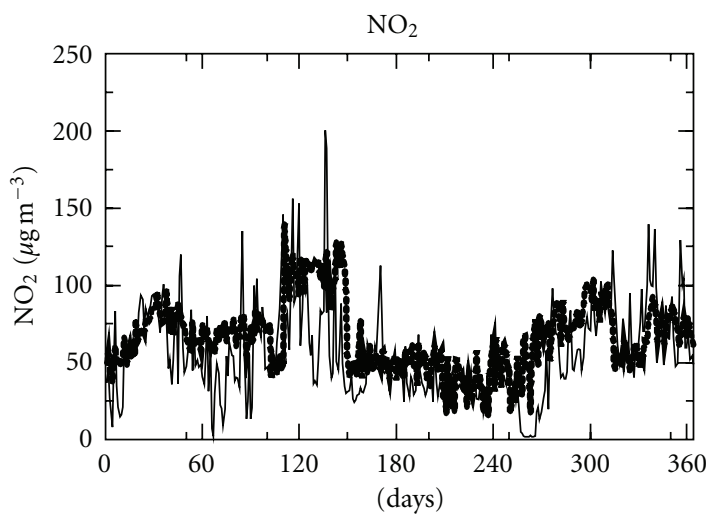

Observed

Prediction with MM5 (0.46)

(e)

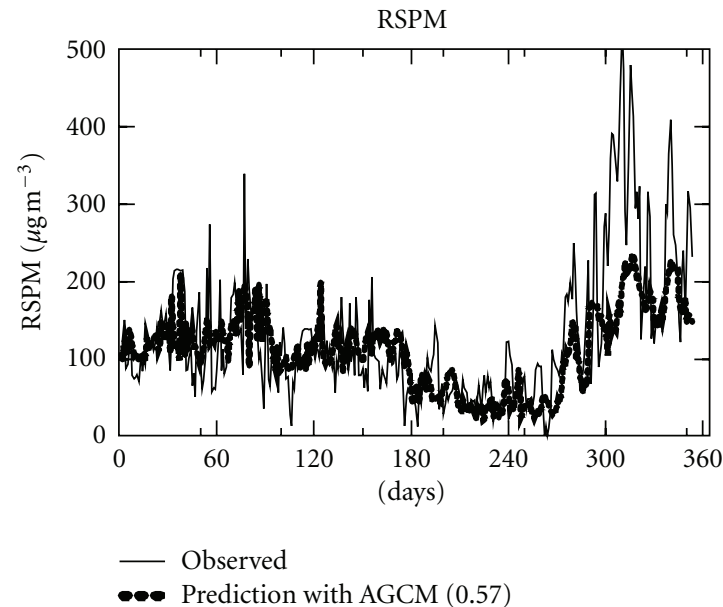

(b)

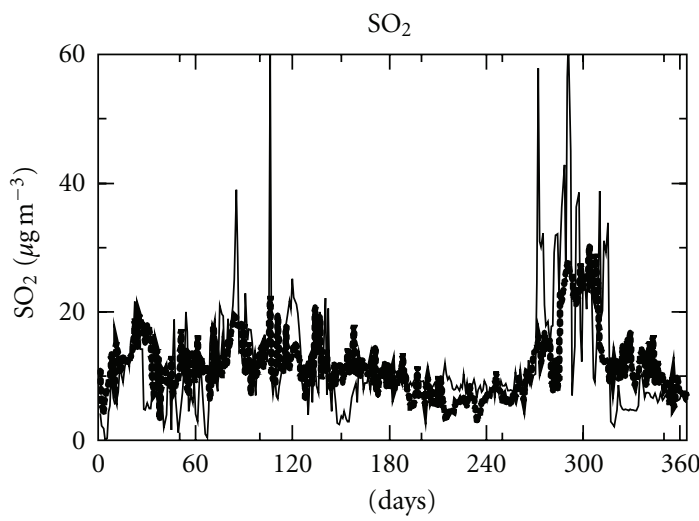

- Observed

๑• Prediction with AGCM (0.5)

(d)

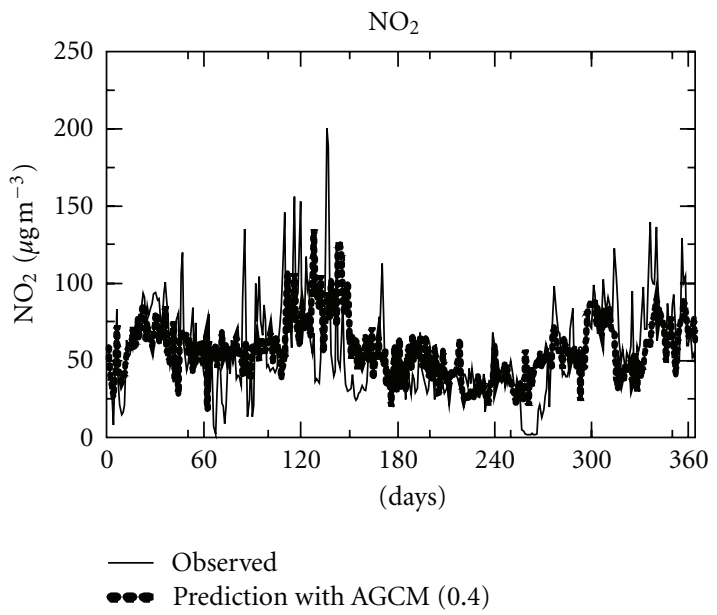

(f)

Figure 2: Daily values of RSPM, $\mathrm{SO}_{2}$, and $\mathrm{NO}_{2}$ over ITO (Delhi) for 2010 as indicated. The left and the right panels indicate, respectively, simulations driven by meteorological fields from MM5 and AGCM forecasts. The numbers in the brackets represent the correlation between observed and predicted pollutant concentration. 
2007

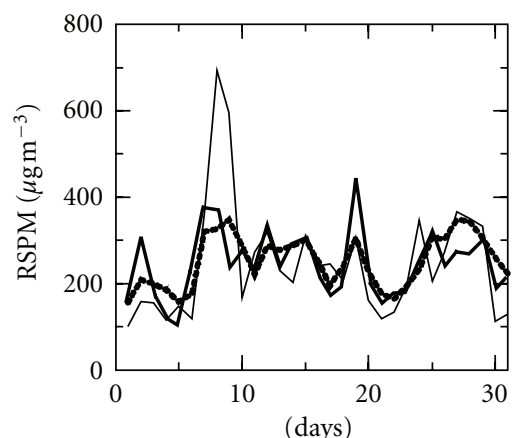

- Observed

— Prediction: MM5 (0.42)

Prediction: AGCM (0.36)

(a)

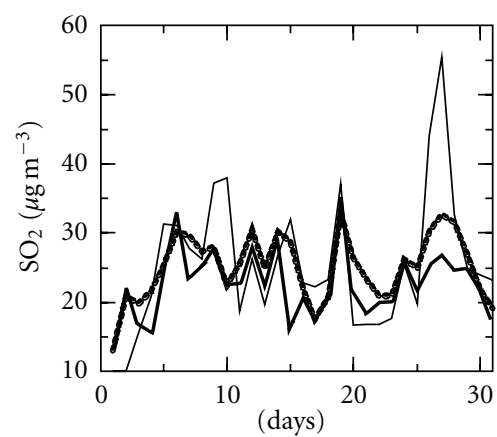

- Observed

— Prediction: MM5 (0.42)

๑๑ Prediction: AGCM (0.46)

(d)

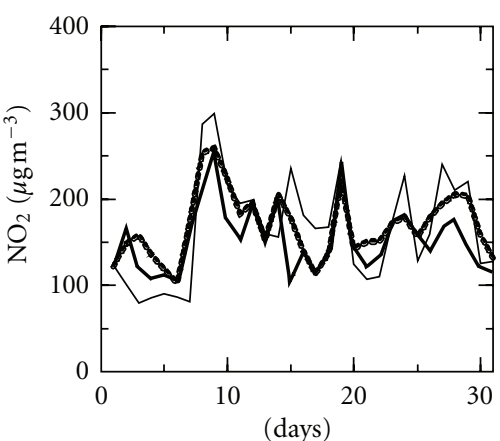

- Observed

Prediction: MM5 (0.37)

๑๑ Prediction: AGCM (0.48)

(g)

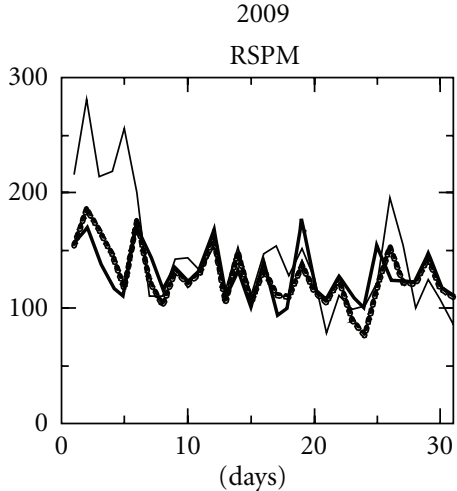

- Observed

— Prediction: MM5 (0.46)

$\bullet$ Prediction: AGCM (0.48)

(b)

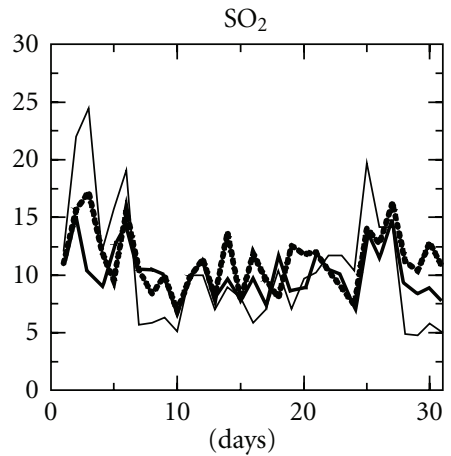

- Observed

— Prediction: MM5 (0.46)

๑๑ Prediction: AGCM (0.4)

(e)

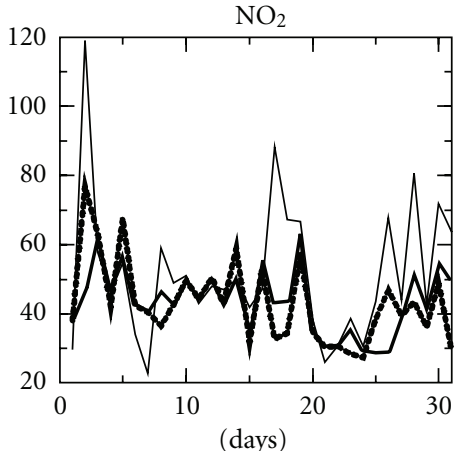

- Observed

Prediction: MM5 (0.45)

Prediction: AGCM (0.5)

(h)
2010

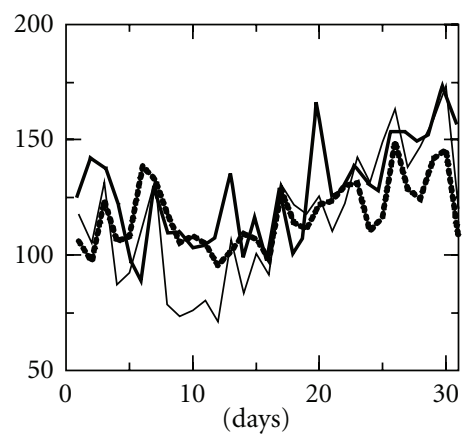

- Observed

— Prediction: MM5 (0.62)

$\bullet$ Prediction: AGCM (0.58)

(c)

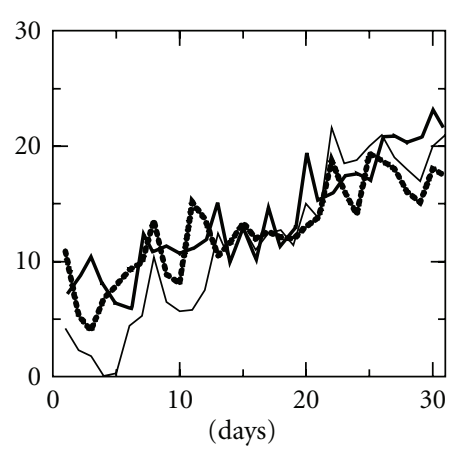

Observed
— Prediction: MM5 $(0.67)$
Prediction: AGCM (0.7)

(f)

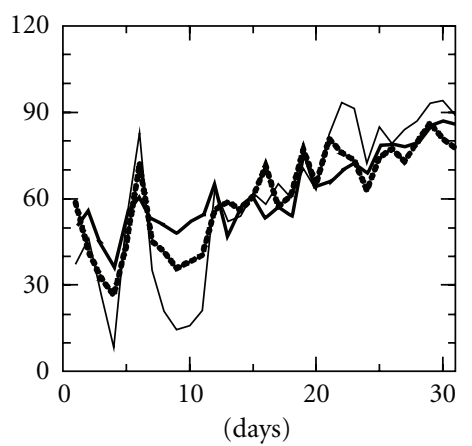

Observed

Prediction: MM5 (0.65)

Prediction: AGCM (0.71)

(i)

FIGURE 3: Comparison of simulated pollutants over ITO (Delhi) for the month of January with meteorological fields derived from AGCM and MM5 forecasts. The left, middle, and the right panels represent results for 2007, 2009, and 2010. The numbers in the brackets represent the correlation between observed and predicted pollutant concentration. 


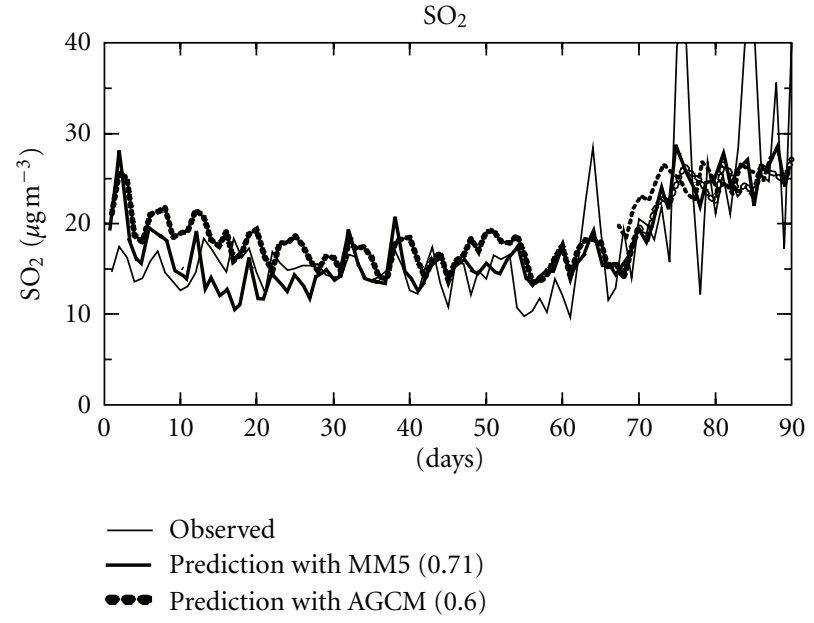

(a)

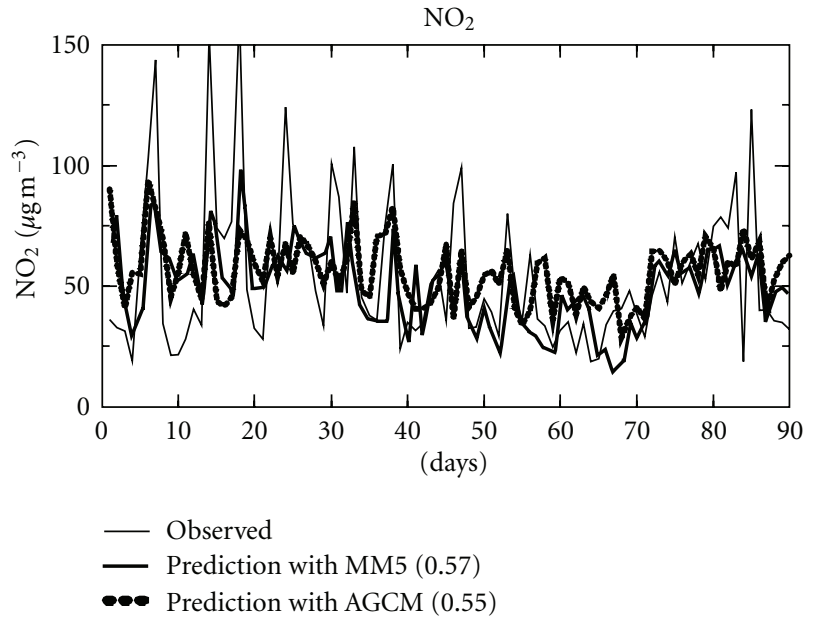

(b)

FIGURE 4: Daily values of $\mathrm{SO}_{2}$ and $\mathrm{NO}_{2}$ over Sirifort (Delhi) for January-March, 2010, as indicated. The meteorological variables have been taken from MM5 and AGCM model. The numbers in the brackets represent the correlation between observed and predicted pollutant concentration. The observed data is from the Central Pollution Control Board (CPCB).

$\mathrm{NO}_{2}$ (Figure 2, middle and bottom panels); high wind speeds allow the pollutants to disperse. Thus the period from July to September is cleaner period in the year.

During May-June, the winds over Delhi turn westerlies, bringing the dust from Thar Desert and arid regions to the west of Delhi [13]. Again the winter maxima appear to be significantly controlled by domestic sources $[13,14]$.

It may be seen that the meteorological fields derived from the two models affect the variability (correlation coefficients in the brackets) in the simulation of pollutant levels over ITO (Delhi). The correlation coefficients between observed and simulated values of pollutants are higher with MM5generated fields than those with AGCM-derived fields. However, the correlation is significant for both cases at $99 \%$ confidence level for the degrees of freedom involved.

To examine the effectiveness of the model for different time periods, we have simulated the fields for the years 2007, 2009, and 2010 over the location ITO (Delhi) for which data is available on RSPM, $\mathrm{SO}_{2}$, and $\mathrm{NO}_{2}$ for the month of January (Figure 3). A comparison of daily values of simulated RSPM, $\mathrm{SO}_{2}$, and $\mathrm{NO}_{2}$ for the three years with MM5 and AGCM fields shows close agreement. It may be seen that the correlation coefficients for all the cases are comparable. The simulations with the two meteorological fields match the overall trends well, although neither model is able to capture some of the observed peaks in 2007 and 2009. Unlike that in the years 2007 and 2009, RSPM shows an increasing trend in the month of January, 2010, in observation. It is interesting that this trend is captured by both simulations, but somewhat better with the AGCM-derived fields, as is evident by higher correlation coefficients for the latter case. This indicates that this characteristic for 2010 is a result of large-scale atmospheric circulation and supports our earlier hypothesis that the global circulation model may provide a better candidate for driving the pollution model in same cases. Consistent with this scenario, the AGCM-derived fields do not show better correlation for 2007 and 2009, for which the observed pollutants have no prominent trends.

Observed data on $\mathrm{SO}_{2}$ and $\mathrm{NO}_{2}$ over the location Siri Fort (Delhi) could be accessed for the duration JanuaryMarch for the year 2010. A comparison of these observations with simulations from MM5- and AGCM-derived fields shows (Figure 4) that the simulations follow the observed features quite closely in general. However, for both $\mathrm{SO}_{2}$ and $\mathrm{NO}_{2}$, the simulations fail to capture the spikes in concentrations: in March for $\mathrm{SO}_{2}$ and in January for $\mathrm{NO}_{2}$.

Comparison of the two simulations over Bandra (Mumbai) for the year 2010 (Figure 5) shows that AGCM is less successful than MM5 in generating the observed concentrations. The improvement due to use of MM5-generated fields is prominent except for RSPM as reflected by the correlation coefficients. The concentrations of RSPM are lower during monsoon months and higher in winter months as expected; however, a similar seasonal variation is also noticed in $\mathrm{NO}_{2}$ over Bandra (Mumbai) (Figure 5, bottom panels). Once again, both models fail to capture most of the observed spikes; however, the correlation between observed and simulated RSPM with MM5 is slightly lower than that for AGCM. This indicates that atmospheric processes primarily control the overall seasonal variations of the pollutants over this location. The large amounts of precipitation in monsoon months reduce atmospheric pollution through wet deposition processes (Figure 5). During the winter, atmospheric dispersion is typically low, and therefore the pollutants will not be as widely dispersed. Another reason for high pollution level in winter is that most of the industries are located in north and north-eastern part of Mumbai. The predominant wind in winter is north and north-east and predominant wind direction in winter cause high pollution levels in Mumbai. Since in our present formalism, we have not included industry as a source, so the forecast values are lower than the observed values, especially for RSPM and $\mathrm{NO}_{2}$. 


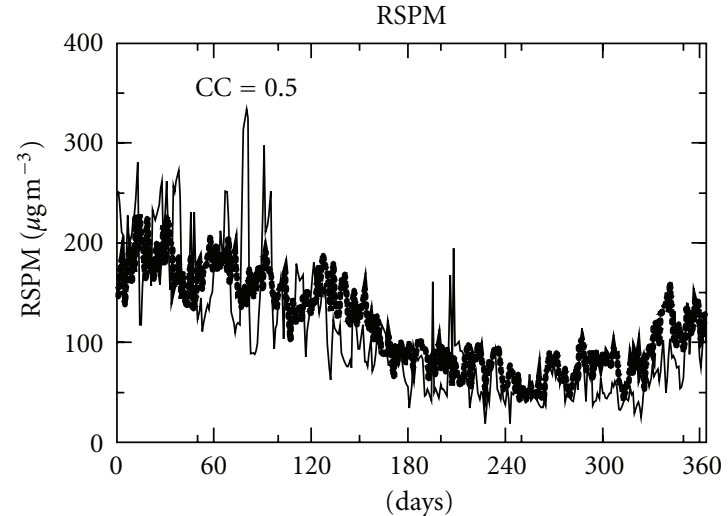

- Observed

œ• Predicted with MM5

(a)

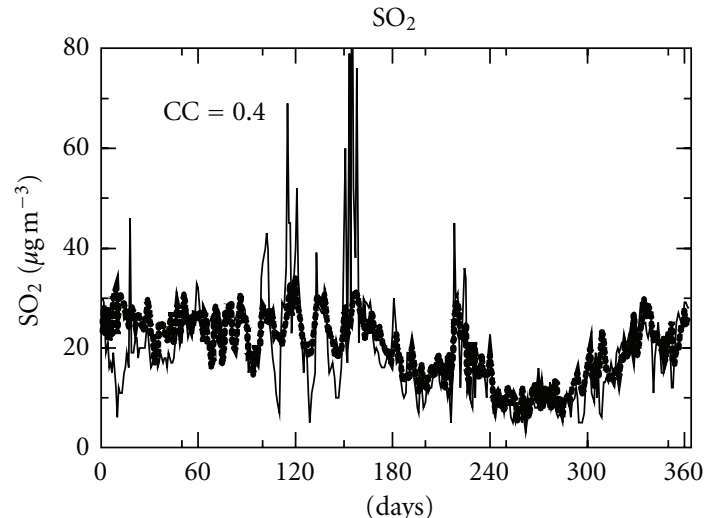

- Observed

œ• Predicted with MM5

(c)

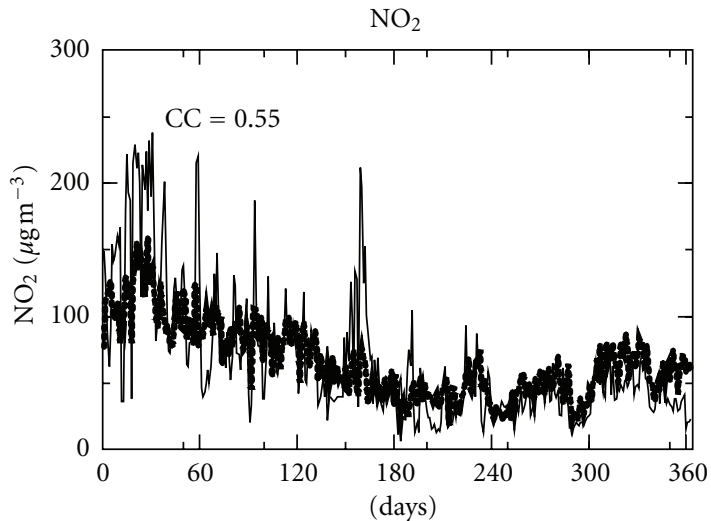

- Observed

$\cdots$ Predicted with MM5

(e)

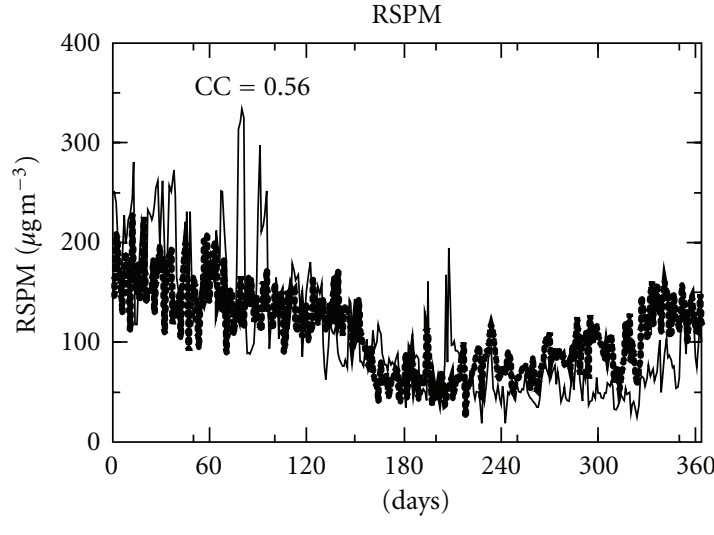

- Predicted with AGCM

(b)

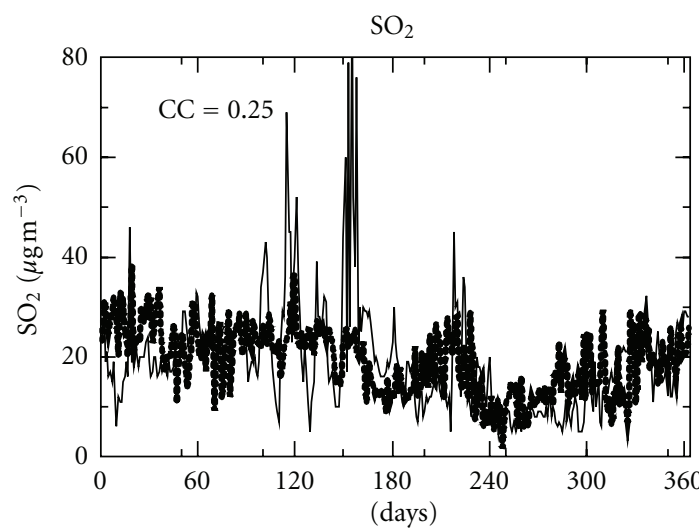

- Observed

•• Predicted with AGCM

(d)

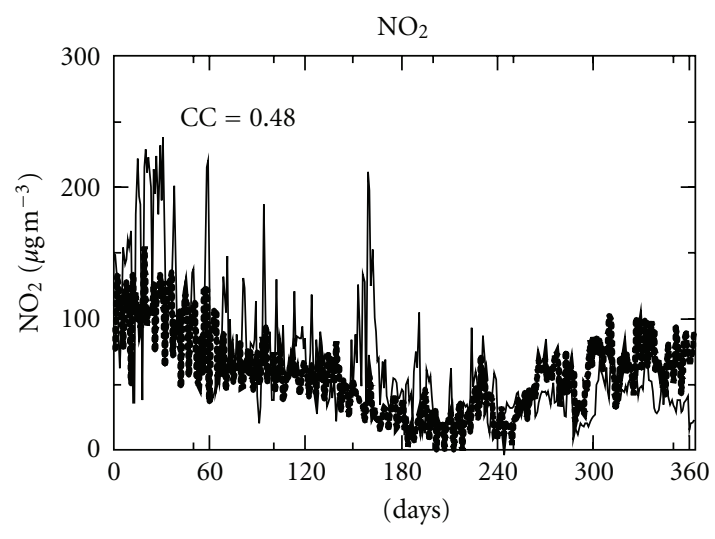

Observed

œ- Predicted with AGCM

(f)

Figure 5: Daily values of the three pollutants over Bandra (Mumbai) for 2010. The left and the right panels indicate, respectively, the simulations driven by MM5- and AGCM-derived meteorological fields. CC is the correlation between observed and predicted pollutant concentration. 


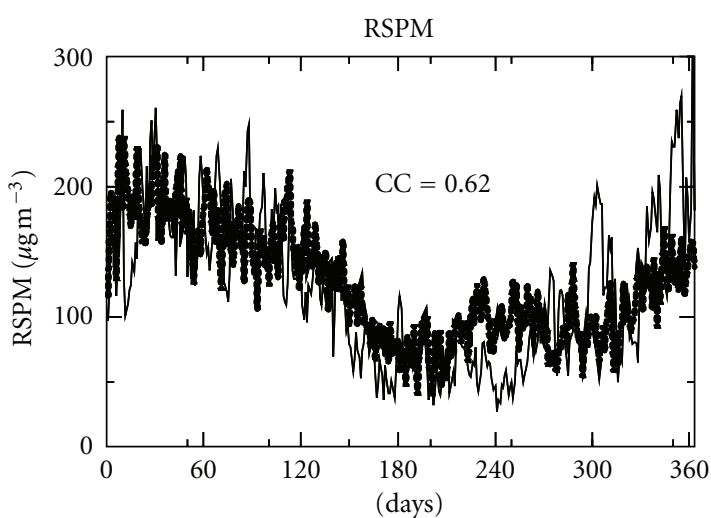

- Observed

œ• Prediction with MM5

(a)

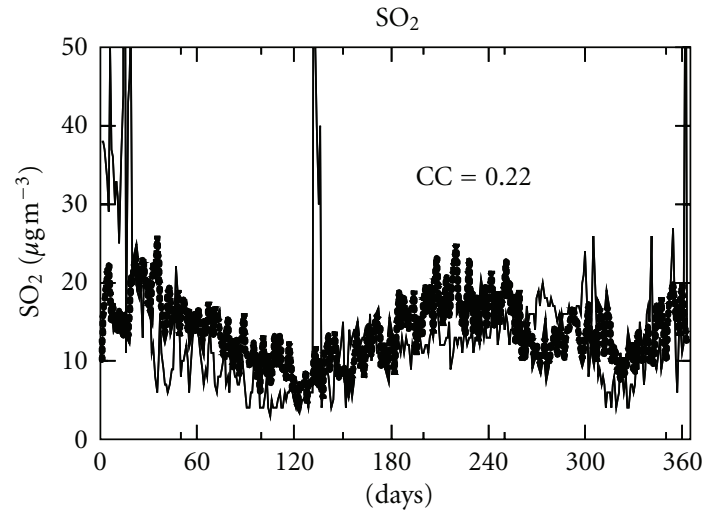

- Observed

•• Prediction with MM5

(c)

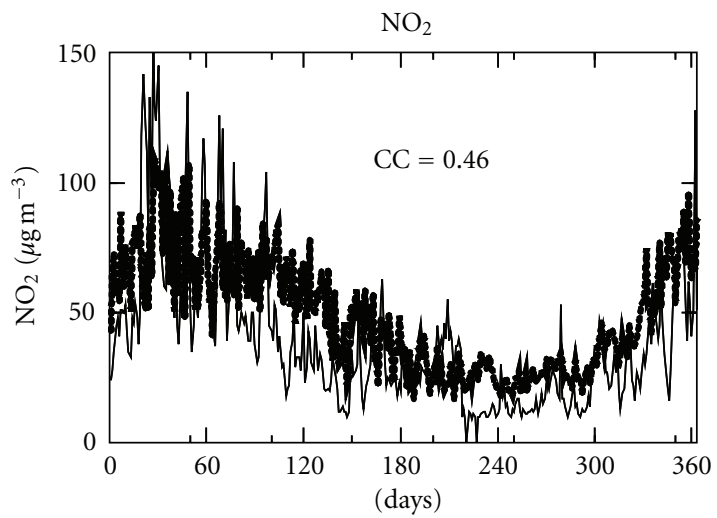

Observed

Prediction with MM5

(e)

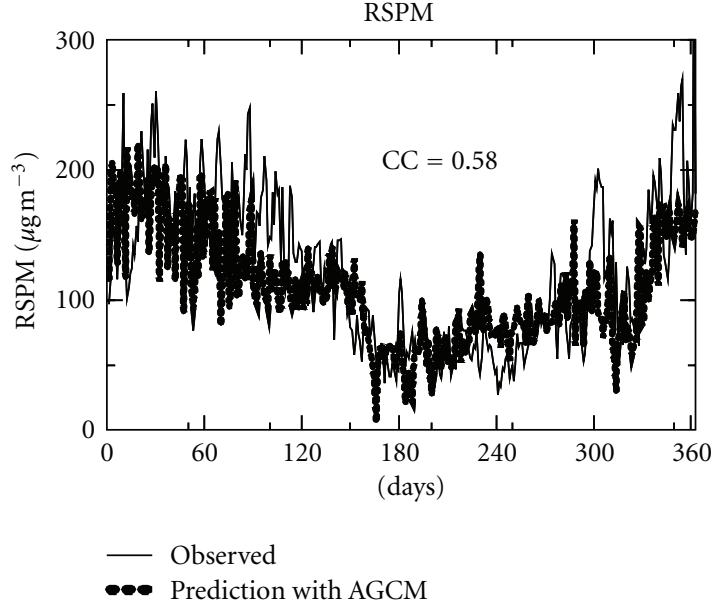

(b)

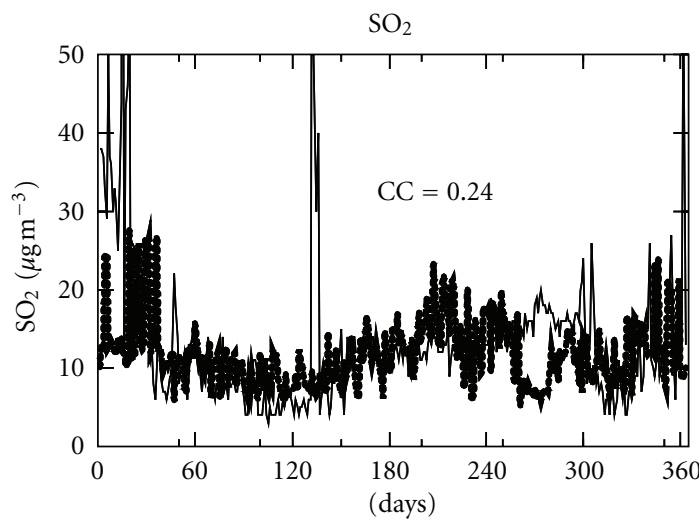

- Observed

œ Prediction with AGCM

(d)

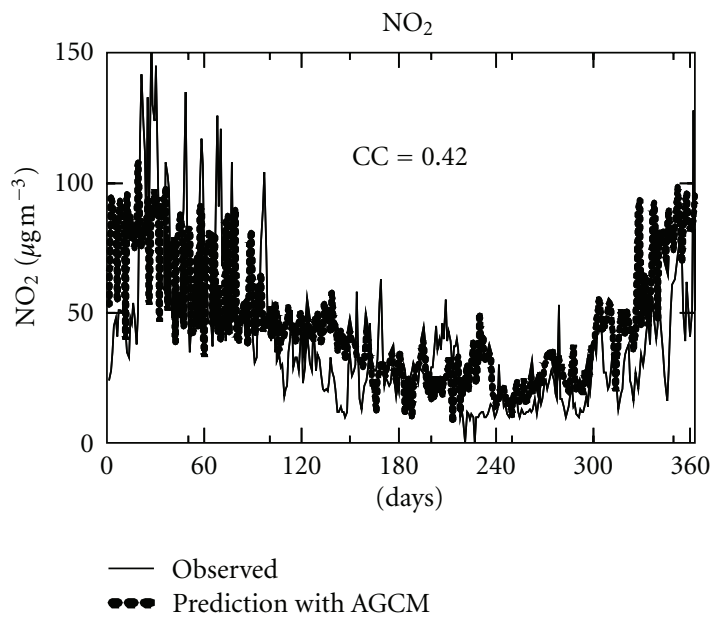

(f)

Figure 6: Daily values of RSPM, $\mathrm{SO}_{2}$, and $\mathrm{NO}_{2}$ over Karve Road (Pune) for 2010. The left and the right panels indicate, respectively, the simulations driven by MM5- and AGCM-derived meteorological fields. CC is the correlation between observed and predicted pollutant concentration. The observed data is from the Maharashtra Pollution Control Board (MPCB). 


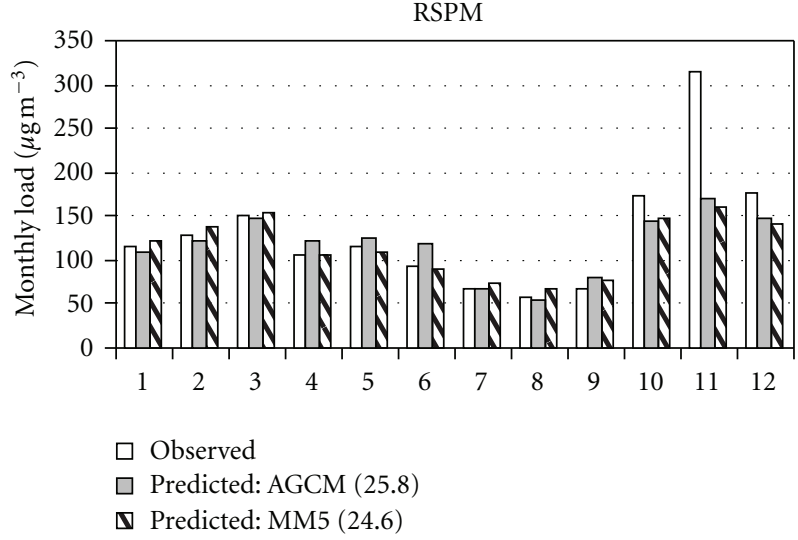

(a)

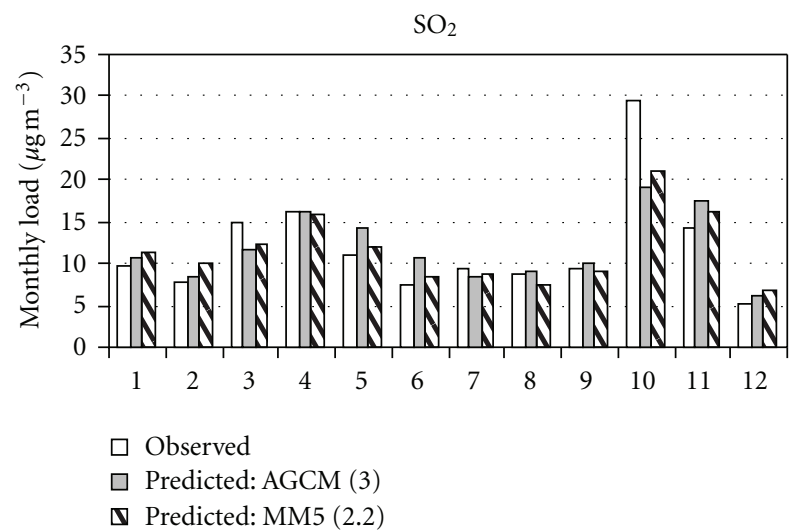

(b)

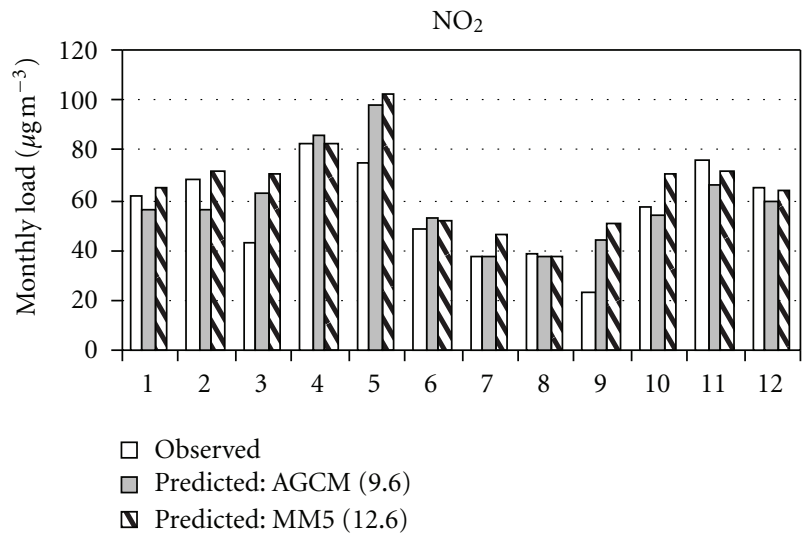

(c)

FIgure 7: Monthly load of RSPM, $\mathrm{SO}_{2}$ and $\mathrm{NO}_{2}$ over ITO (Delhi) for 2010. The meteorological data are taken from AGCM and MM5 model. The numbers in the brackets represent the average error between 12 values of observation and prediction. The observed data is from the Central Pollution Control Board (CPCB).

TABLE 5: Annual load and average absolute error between observation and prediction of RSPM, $\mathrm{SO}_{2}$, and $\mathrm{NO}_{2}$ for the three locations: ITO (Delhi), Bandra (Mumbai), and Karve Road (Pune) for the year 2010.

\begin{tabular}{|c|c|c|c|c|c|c|c|c|c|c|c|c|}
\hline \multirow{3}{*}{ location } & \multicolumn{4}{|c|}{ RSPM } & \multicolumn{4}{|c|}{$\mathrm{SO}_{2}$} & \multicolumn{4}{|c|}{$\mathrm{NO}_{2}$} \\
\hline & \multicolumn{2}{|c|}{ Annual load } & \multicolumn{2}{|c|}{ Average absolute error } & \multicolumn{2}{|c|}{ Annual load } & \multicolumn{2}{|c|}{ Average absolute error } & \multicolumn{2}{|c|}{ Annual load } & \multicolumn{2}{|c|}{$\begin{array}{l}\text { Average absolute } \\
\text { error }\end{array}$} \\
\hline & MM5 & AGCM & MM5 & AGCM & MM5 & AGCM & MM5 & AGCM & MM5 & AGCM & MM5 & AGCM \\
\hline ITO (Delhi) & 40488 & 38836 & 47.3 & 53.5 & 4439 & 4202 & 4.1 & 6.4 & 21005 & 24168 & 22 & 21.3 \\
\hline $\begin{array}{l}\text { Bandra } \\
\text { (Mumbai) }\end{array}$ & 43113 & 40472 & 32.4 & 37.3 & 7342 & 6979 & 5.4 & 7.6 & 24172 & 21002 & 23.3 & 30.6 \\
\hline $\begin{array}{l}\text { Karve Road } \\
\text { (Pune) }\end{array}$ & 45550 & 41935 & 35 & 34.8 & 5022 & 4313 & 7.2 & 5.5 & 17877 & 16953 & 18.1 & 19.5 \\
\hline
\end{tabular}

It should be noted that, unlike the case for Delhi, the AGCM configuration was not optimized for Bandra (Mumbai). Thus, the relatively poor performance of AGCMderived fields over Bandra (Mumbai) could be a reflection of this fact.

Prominent seasonal cycles in RSPM and $\mathrm{NO}_{2}$ are also seen (Figure 6) at Karve Road (Pune). The simulated concentrations follow the observed variability quite closely, as a comparison of daily observed and simulated values of RSPM, $\mathrm{SO}_{2}$, and $\mathrm{NO}_{2}$ shows. It is interesting to note that the quality of the simulations with MM5 and AGCM is comparable for all the three pollutants.

A comparison of monthly average values of three pollutants over ITO (Delhi), computed by averaging respective daily values, shows both configurations to possess comparable skill (Figure 7), with nearly equal values of average errors over 12 months (numbers in the brackets). This indicates that the variability of the concentrations at monthly scale can be captured well by using either a meso-scale model or an AGCM. 


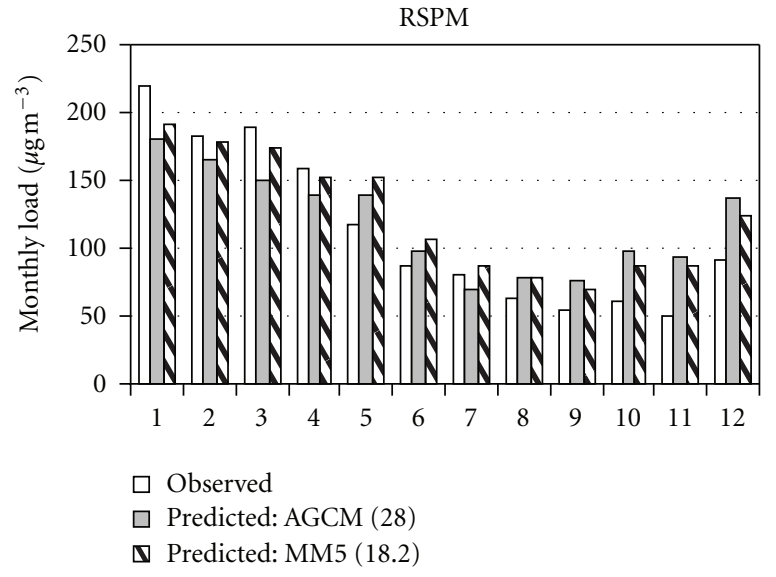

(a)

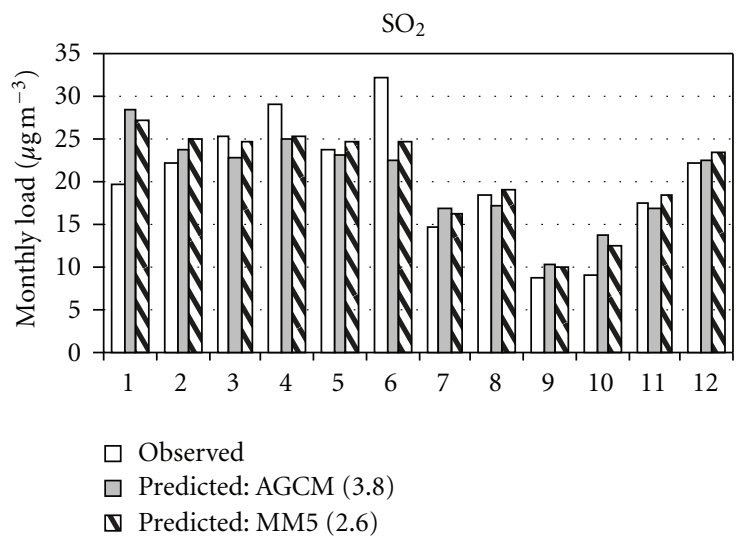

(c)

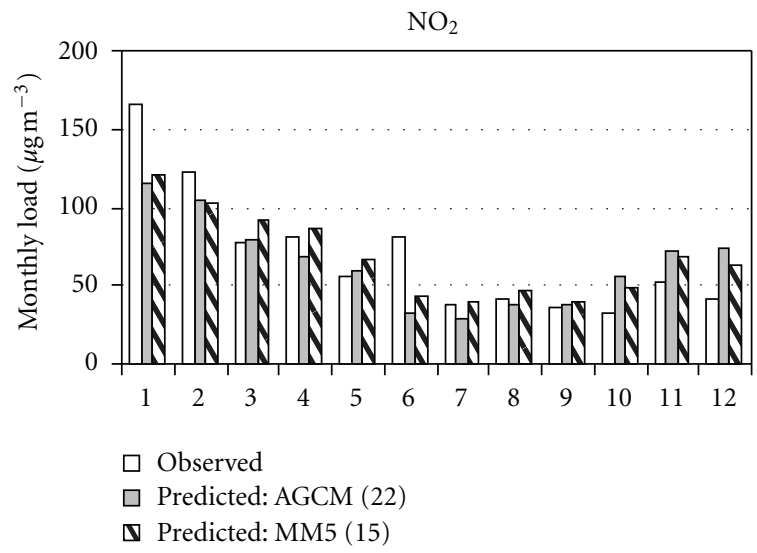

(e)

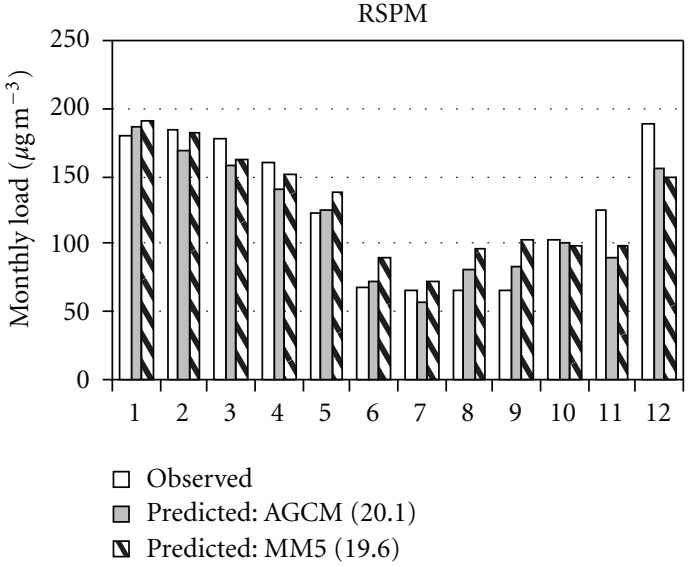

(b)

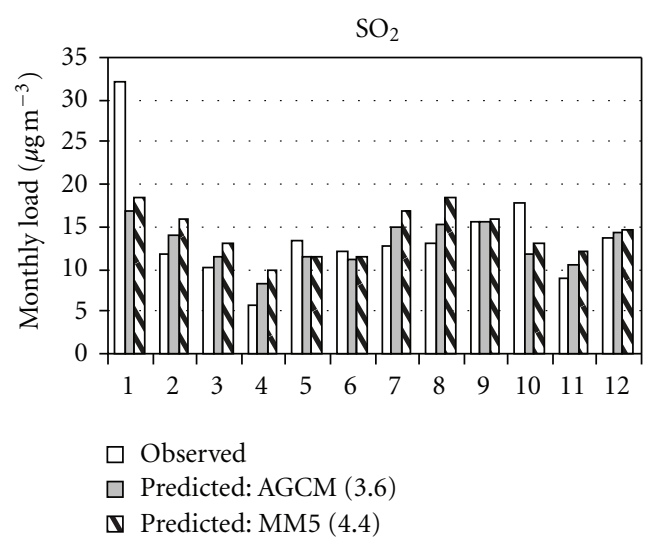

(d)

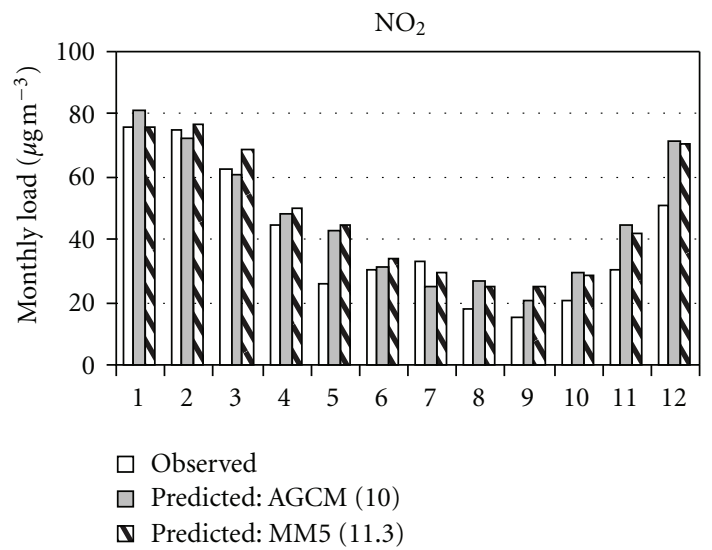

(f)

Figure 8: Monthly load of different pollutants over Bandra (Mumbai) (left panels) and Karve Road (Pune) (right panels) for 2010. The meteorological data are taken from AGCM and MM5 models. The numbers in the brackets represent the average error between 12 values of observation and prediction. The observed data is from the Maharashtra Pollution Control Board (MPCB).

The monthly averaged values for Bandra (Mumbai) and Karve Road (Pune) for 2010 (Figure 8, left and right panels, respectively) also support similar conclusions. Although each of these locations exhibits distinct observed seasonal cycle, the simulations reproduce them reasonably well.
A summary of skill in the simulation of annual load of pollutants at three sites by MM5 and AGCM shows comparable error with respect to respective observations (Table 5). Although the errors with MM5 fields are marginally lower than those with AGCM fields, there is no systematic 
difference: the absolute errors, averaged over the 365 days, are quite small for all the cases.

\section{Conclusions}

The results of the present study show that given the local sources, especially vehicular data, the air pollution model driven by meteorological fields can reproduce observed features quite well. Although the model has been initially developed and tested for the Delhi Air basin, it works well also for the two other locations, Bandra (Mumbai) and Karve Road (Pune). As expected, the errors are more at daily scale; however, the simulations closely follow the observed features at monthly scale (Figures 7 and 8); thus these model configurations provide powerful tools for studying air pollution over different Air basin.

The results also show that both AGCM and the mesoscale model provide comparable performance. This is not surprising since AGCM has the advantage of better simulating the large-scale features of the meteorological fields (close to global setting) while a meso-scale model has the advantage of higher spatial resolution. This is evident from the results for the month of January for 2007, 2009, and 2010 over Delhi (Figure 3); while both models perform comparably for 2007 and 2009; the AGCM-derived fields simulated the unusual behaviors in 2010 better.

The spikes in observation, such as for $\mathrm{SO}_{2}$ over Karve Road (Pune), may represent special events which if regular such as the color festival "Holi" need to be included in the model. Dust particles in the colours used during Holi result in the increase levels of particulate matters. Again burning of fire crackers during the light festival "Diwali" results in high levels of air pollution. The absence of these spikes in simulations is primarily responsible for the errors in monthly averaged values (Figures 7 and 8) and the annual load (Table 5).

As noted earlier, the AGCM-derived fields performed relatively poorly over Bandra (Mumbai) and Karve Road (Pune). While this could be due to general performance of the AGCM over these locations, it is possible that model optimization that was carried out for Delhi but not for the other two locations has an important role to play; this is certainly an important avenue for future development.

\section{Acknowledgment}

This work was supported by a research grant under the Network Project, Integrated CSIR, Government of India.

\section{References}

[1] F. A. Adekola, O. A. Eletta, and S. A. Atanda, "Determination of the levels of some heavy metals in urban run-off sediments in Ilorin and Lagos, Nigeria," Journal of Applied Sciences and Environmental Management, vol. 6, no. 2, pp. 23-26, 2002.

[2] C. R. Odoemenam, Evaluation and modelling of air pollution Minna metropolis as case study [A Bachelor of Engineering Thesis], Chemical Engineering Department, Fedaral University of Technology, Minna, Nigeria, 2002.
[3] F. U. Nwafulugo, Determination of atmospheric pollutants concentration using meteorological data [M.S. thesis of Engineering Research Project], Chemical Engineering Department, Fedaral University of Technology, Minna, Nigeria, 2001.

[4] S. Vardoulakis, B. E. A. Fisher, K. Pericleous, and N. GonzalezFlesca, "Modelling air quality in street canyons: a review," Atmospheric Environment, vol. 37, no. 2, pp. 155-182, 2003.

[5] H. Afshar and M. R. Delavar, "A GIS-based air pollution modeling in Tehran," Environmental Informatics Archives, vol. 5, pp. 557-566, 2007.

[6] B. Fisher, J. Kukkonen, M. Piringer, M. W. Rotach, and M. Schatzmann, "Meteorology applied to urban air pollution problems: concepts from COST 715," Atmospheric Chemistry and Physics, vol. 6, no. 2, pp. 555-564, 2006.

[7] R. B. Banta, C. J. Senff, R. J. Alvarez et al., "Dependence of peak daily ozone concentrations in Houston, Texas on the sea breeze and meteorological variables," in Proceedings of the 8th Symposium on the Urban Environment, Phoenix, Ariz, USA, January 2009, J13.3.

[8] M. Cope and D. Hess, "Air quality forecasting: a review and comparison of the approaches used internationally and in Australia," Clean Air and Environmental Quality, vol. 39, no. 1, pp. 52-60, 2005.

[9] M. W. Gery, G. Z. Whitten, and J. P. Killus, "Development and Testing of the CBM-IV for Urban and Regional Modeling," US Environmental Protection Agency, EPA600/388012, 1988.

[10] G. Grivas and A. Chaloulakou, "Artificial neural network models for prediction of $\mathrm{PM}_{10}$ hourly concentrations, in the Greater Area of Athens, Greece," Atmospheric Environment, vol. 40, no. 7, pp. 1216-1229, 2006.

[11] T. Otte, G. Pouliot, J. E. Pleim et al., "Linking the Eta model with the Community Multiscale Air Quality (CMAQ) modeling system to build a national air quality forecasting system," Weather and Forecasting, vol. 20, pp. 367-384, 2005.

[12] J. N. McHenry, W. F. Ryan, N. L. Seamn et al., "A real-time eulerian photochemical model forecast system," Bulletin of the American Meteorological Society, vol. 85, no. 4, pp. 525-548, 2004.

[13] P. Goswani and J. Baruah, "Simulation of daily variation of suspended particulate matter over Delhi: relative roles of vehicular emission, dust, and domestic appliances," Monthly Weather Review, vol. 136, no. 9, pp. 3597-3607, 2008.

[14] P. Goswami and J. Baruah, "Urban air pollution: process identification, impact analysis and evaluation of forecast potential," Meteorology and Atmospheric Physics, vol. 110, no. 3, pp. 103-122, 2011.

[15] Maharashtra Pollution Control Board (MPCB), "Report on environmental status of Pune region," Tech. Rep., Kalpataru point, Sion Circle, Sion (east) Mumbai, India, 2004-2005.

[16] P. Goyal and T. V. B. P. S. R. Krishna, "Various methods of emission estimation of vehicular traffic in Delhi," Transportation Research Part D, vol. 3, no. 5, pp. 309-317, 1998.

[17] A. Das and J. Parikh, "Transport scenarios in two metropolitan cities in India: Delhi and Mumbai," Energy Conversion and Management, vol. 45, no. 15-16, pp. 2603-2625, 2004.

[18] Pune Vehicle Activity Study, University of California at Riverside, Global Sustainable Systems Research, 2004.

[19] CPCB, Guidelines for Ambient Air Quality Monitoring, Series: NAAQMS/../2003-04, National Ambient Air Quality Monitoring, April 2003.

[20] NEERI, Review of GEMS/Air Monitoring Stations in South Asia Region, WHO, Geneva, Switzerland, 1996. 
[21] M. K. Ghose, "Pollution due to air borne dust particles in coal mining its monitoring and abatement measures," Mine Technology, vol. 10, no. 1, pp. 91-95, 1989.

[22] M. K. Ghose and S. R. Majee, "Assessment of the impact on the air environment due to opencast coal mining — an Indian case study," Atmospheric Environment, vol. 34, no. 17, pp. 27912796, 2000.

[23] IS, 5182 (Part II), "Indian Standard Methods for the Measurement of Air Quality," 1969.

[24] IS: 5182 (Part IV), "Indian Standard Methods for the Measurement of Air Quality," 1976.

[25] M. K. Ghose and S. K. Banerjee, "Status of air pollution caused by coal washery projects in India," Environmental Monitoring and Assessment, vol. 38, no. 1, pp. 97-105, 1995.

[26] APHA, Methods of Air Sampling and Analysis, APHA, Washington, DC, USA, 2nd edition, 1977.

[27] M. K. Ghose, S. R. Majee, and P. K. Sinha, "Monitoring and assessment of impact on air environment caused by coke plant operations in India," International Journal of Environmental Studies, vol. 56, no. 4, pp. 475-482, 1999.

[28] D. Byun and K. L. Schere, "Review of the governing equations, computational algorithms, and other components of the models-3 Community Multiscale Air Quality (CMAQ) modeling system," Applied Mechanics Reviews, vol. 59, no. 1-6, pp. 51-76, 2006.

[29] M. Sharan and S. G. Gopalakrishnan, "Mathematical modeling of diffusion and transport of pollutants in the atmospheric boundary layer," Pure and Applied Geophysics, vol. 160, no. 1-2, pp. 357-394, 2003.

[30] O. P. Sharma, H. C. Upadhyaya, Th. Braine-Bonnaire, and R. Sadourney, "Experiments on regional forecasting using a stretched coordinate general circulation model. Short and medium range numerical weather prediction," Journal of the Meteorological Society of Japan, vol. 65, pp. 263-271, 1987.

[31] F. Hourdin, I. Musat, S. Bony et al., "The LMDZ4 general circulation model: climate performance and sensitivity to parametrized physics with emphasis on tropical convection," Climate Dynamics, vol. 19, pp. 3445-3482, 2006.

[32] M. Tiedtke, "A comprehensive mass flux scheme for cumulus parameterization in large-scale models," Monthly Weather Review, vol. 117, no. 8, pp. 1779-1800, 1989.

[33] P. A. Goswami, H. C. U. Mandal, and F. Hourdin, "Advance forecasting of cyclone track over Indian Ocean using a global circulation model," Mausam, vol. 57, pp. 111-118, 2006.

[34] P. Goswami and K. C. Gouda, "Comparative evaluation of two ensembles for long-range forecasting of monsoon rainfall," Monthly Weather Review, vol. 137, no. 9, pp. 2893-2907, 2009.

[35] P. Goswami and K. C. Gouda, "Evaluation of a dynamical basis for advance forecasting of the date of onset of monsoon rainfall over India," Monthly Weather Review, vol. 138, no. 8, pp. 3120-3141, 2010.

[36] R. A. Anthes and T. T. Warner, "Development of hydrodynamic models suitable for air pollution and other meso meteorological studies," Monthly Weather Review, vol. 106, pp. 10451078, 1978.

[37] J. Dudhia, "A nonhydrostatic version of the Penn StateNCAR mesoscale model: validation tests and simulation of an Atlantic cyclone and cold front," Monthly Weather Review, vol. 121, no. 5, pp. 1493-1513, 1993.

[38] G. Grell, J. Dudhia, and D. Stauffer, "A description of the fifthgeneration penn state/NCAR mesoscale model (MM5)," NCAR Technical Note, no. NCAR/TN-398+STR, 1994.
[39] Z. Toth, E. Kalnay, S. M. Tracton, R. Wobus, and J. Irwin, "A synoptic evaluation of the NCEP ensemble," Weather and Forecasting, vol. 12, no. 1, pp. 140-153, 1997.

[40] M. Lal, U. Cubasch, J. Perlwitz, and J. Waszkewitz, "Simulation of the Indian monsoon climatology in ECHAM3 climate model: sensitivity to horizontal resolution," International Journal of Climatology, vol. 17, no. 8, pp. 847-858, 1997.

[41] K. R. Sperber, S. Hameed, G. L. Potter, and J. S. Boyle, "Simulation of the northern summer monsoon in the ECMWF model: sensitivity to horizontal resolution," Monthly Weather Review, vol. 122, no. 11, pp. 2461-2481, 1994. 

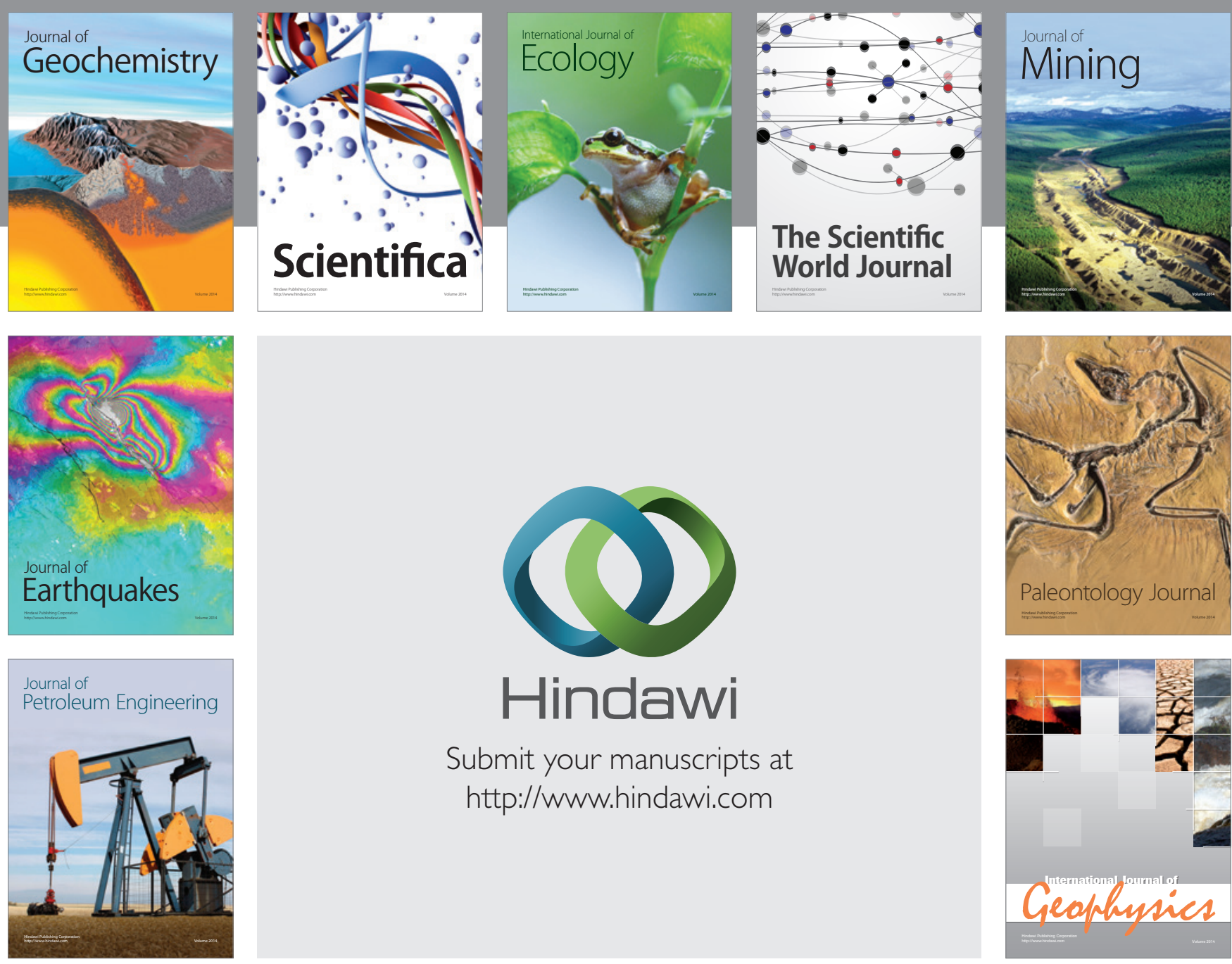

Submit your manuscripts at

http://www.hindawi.com
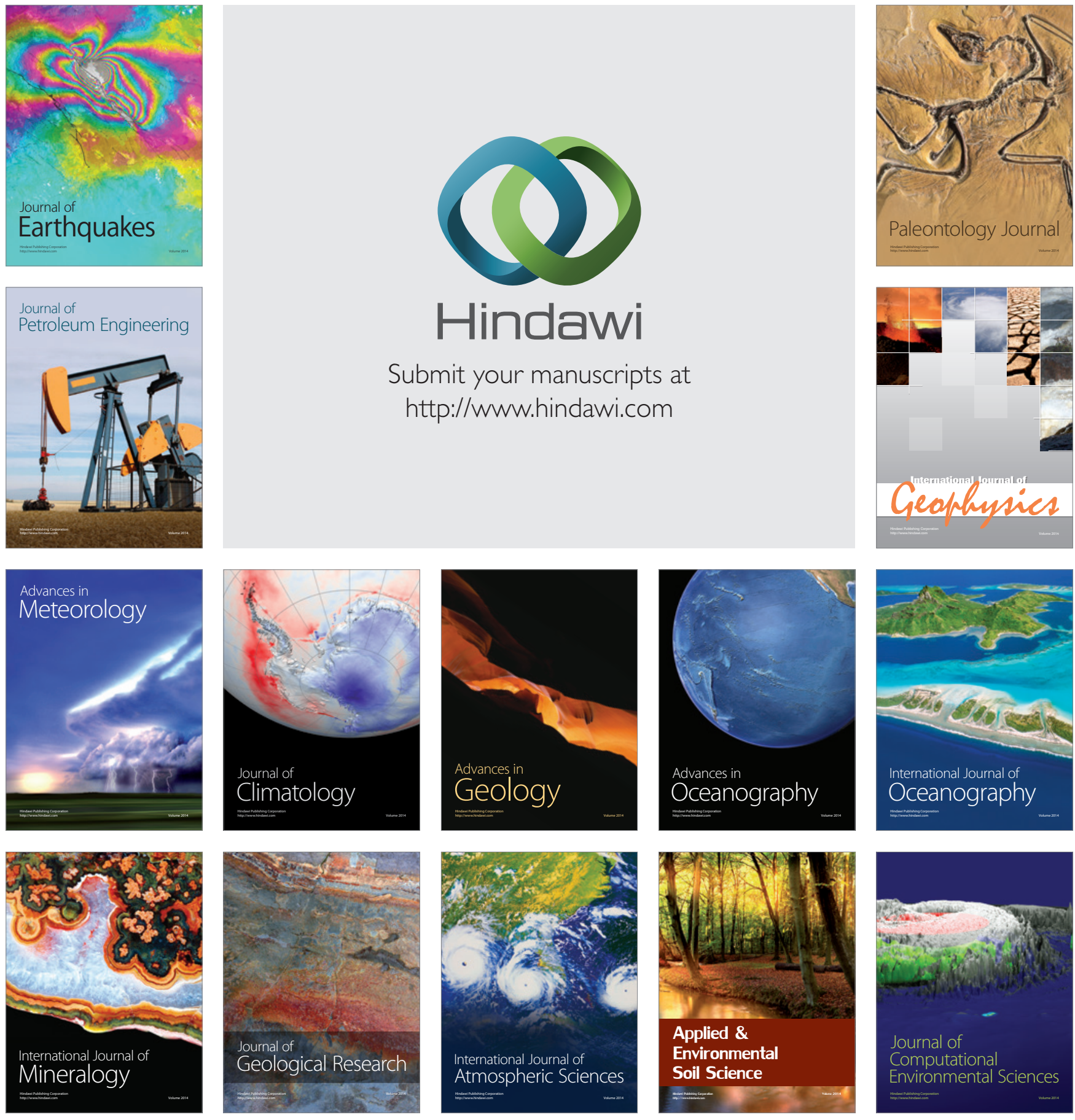